\title{
The future of Earth observation in hydrology
}

\author{
Matthew F. McCabe ${ }^{1}$, Matthew Rodell ${ }^{2}$, Douglas E. Alsdorf ${ }^{3}$, Diego G. Miralles ${ }^{4}$, Remko Uijlenhoet ${ }^{5}$, \\ Wolfgang Wagner ${ }^{6,7}$, Arko Lucieer ${ }^{8}$, Rasmus Houborg ${ }^{1}$, Niko E. C. Verhoest ${ }^{4}$, Trenton E. Franz ${ }^{9}$, Jiancheng Shi ${ }^{10}$, \\ Huilin Gao ${ }^{11}$, and Eric F. Wood ${ }^{12}$ \\ ${ }^{1}$ Water Desalination and Reuse Center, King Abdullah University of Science and Technology, Thuwal, Saudi Arabia \\ ${ }^{2}$ Hydrological Science Laboratory, Goddard Space Flight Center (GSFC), National Aeronautics and Space \\ Administration (NASA), Greenbelt, Maryland, USA \\ ${ }^{3}$ Byrd Polar and Climate Research Center, The Ohio State University, Columbus, Ohio, USA \\ ${ }^{4}$ Laboratory of Hydrology and Water Management, Ghent University, Ghent, Belgium \\ ${ }^{5}$ Hydrology and Quantitative Water Management Group, Wageningen University, Wageningen, the Netherlands \\ ${ }^{6}$ Department of Geodesy and Geoinformation, Technische Universität Wien, Vienna, Austria \\ ${ }^{7}$ Center for Water Resource Systems, Technische Universität Wien, Vienna, Austria \\ ${ }^{8}$ School of Land and Food, University of Tasmania, Hobart, TAS 7001, Australia \\ ${ }^{9}$ School of Natural Resources, University of Nebraska-Lincoln, Lincoln, Nebraska 68583, USA \\ ${ }^{10}$ State Key Laboratory of Remote Sensing Science, Institute of Remote Sensing and Digital Earth, Chinese Academy of \\ Sciences and Beijing Normal University, Beijing, China \\ ${ }^{11}$ Zachry Department of Civil Engineering, Texas A \& M University, College Station, Texas 77843, USA \\ ${ }^{12}$ Department of Civil and Environmental Engineering, Princeton University, Princeton, New Jersey, USA
}

Correspondence to: Matthew F. McCabe (matthew.mccabe@kaust.edu.sa)

Received: 2 February 2017 - Discussion started: 9 February 2017

Revised: 1 June 2017 - Accepted: 7 June 2017 - Published: 28 July 2017

\begin{abstract}
In just the past 5 years, the field of Earth observation has progressed beyond the offerings of conventional space-agency-based platforms to include a plethora of sensing opportunities afforded by CubeSats, unmanned aerial vehicles (UAVs), and smartphone technologies that are being embraced by both for-profit companies and individual researchers. Over the previous decades, space agency efforts have brought forth well-known and immensely useful satellites such as the Landsat series and the Gravity Research and Climate Experiment (GRACE) system, with costs typically of the order of 1 billion dollars per satellite and with concept-to-launch timelines of the order of 2 decades (for new missions). More recently, the proliferation of smartphones has helped to miniaturize sensors and energy requirements, facilitating advances in the use of CubeSats that can be launched by the dozens, while providing ultra-high (3$5 \mathrm{~m}$ ) resolution sensing of the Earth on a daily basis. Startup companies that did not exist a decade ago now operate more satellites in orbit than any space agency, and at costs that are a mere fraction of traditional satellite missions.
\end{abstract}

With these advances come new space-borne measurements, such as real-time high-definition video for tracking air pollution, storm-cell development, flood propagation, precipitation monitoring, or even for constructing digital surfaces using structure-from-motion techniques. Closer to the surface, measurements from small unmanned drones and tethered balloons have mapped snow depths, floods, and estimated evaporation at sub-metre resolutions, pushing back on spatio-temporal constraints and delivering new process insights. At ground level, precipitation has been measured using signal attenuation between antennae mounted on cell phone towers, while the proliferation of mobile devices has enabled citizen scientists to catalogue photos of environmental conditions, estimate daily average temperatures from battery state, and sense other hydrologically important variables such as channel depths using commercially available wireless devices. Global internet access is being pursued via highaltitude balloons, solar planes, and hundreds of planned satellite launches, providing a means to exploit the "internet of things" as an entirely new measurement domain. Such global 
access will enable real-time collection of data from billions of smartphones or from remote research platforms. This future will produce petabytes of data that can only be accessed via cloud storage and will require new analytical approaches to interpret. The extent to which today's hydrologic models can usefully ingest such massive data volumes is unclear. Nor is it clear whether this deluge of data will be usefully exploited, either because the measurements are superfluous, inconsistent, not accurate enough, or simply because we lack the capacity to process and analyse them. What is apparent is that the tools and techniques afforded by this array of novel and game-changing sensing platforms present our community with a unique opportunity to develop new insights that advance fundamental aspects of the hydrological sciences. To accomplish this will require more than just an application of the technology: in some cases, it will demand a radical rethink on how we utilize and exploit these new observing systems.

\section{Introduction}

The capacity to observe the hydrosphere from the vantage point of space has redefined not only our perspective of Earth as an interconnected system, but also how we describe the dynamic processes that occur above, on, and beneath its surface. The year 2017 marks the 60th anniversary of the launch of Sputnik 1, a polished metal sphere of less than $60 \mathrm{~cm}$ diameter that became the first man-made object placed into orbit. Although only broadcasting dual-frequency radio transmissions over a short 21-day period (until the batteries ran out), Sputnik had an indelible impact on humanity's perception of space, triggering the "space race" and heralding in a new era of Earth observation (EO). Space was to become the new frontier. While the earliest satellite systems had a military reconnaissance focus, the value of space-based sensors for monitoring weather and climate was quickly recognized (Nordberg, 1965). Several meteorology-focused systems were launched in the years following Sputnik, including the Television and InfraRed Observation Satellite (TIROS 1) in 1960, Nimbus 1 in 1964, and the Environmental Science Services Administration (ESSA-1) satellite in 1966. However, it would be 15 years post-Sputnik before the first civilian-focused digital multispectral sensors were launched on-board the inaugural Landsat 1 mission in 1972, a program that has continued uninterrupted for more than 4 decades (Wulder et al., 2008), providing an unrivalled record of terrestrial change and dynamics. Since these early satellite missions there have been considerable and dramatic advances in remote observation platforms and the types of measurements available from them. Evolving from early panchromatic and red-green-blue (RGB) or R-G-near-infrared (NIR) imagery (De Wulf et al., 1990), sensor technology has expanded to include multi- and hyperspectral visible to near-infrared bands (VNIR) (Houborg et al., 2015), multi-band thermal (Roberts et al., 2012), multi-channel microwave emissions (Njoku and Li, 1999), as well as radar and lidar techniques (Mace et al., 2009), all of which have advanced and redefined our knowledge and understanding of the Earth system.

From a hydrological sciences perspective, remote sensing has driven process insights and provided new and independent datasets that span the range of water cycle components. Recent studies such as Lettenmaier et al. (2015) provide a retrospective assessment of these developments and the progress of satellite observations in hydrology, complimenting earlier reviews of Schmugge et al. (2002) and Tang et al. (2009). In addition, process-focused contributions have examined remotely sensed evaporation (Kalma et al., 2008; Wang and Dickinson, 2012), soil moisture (Njoku and Entekhabi, 1996; Wagner et al., 2007), precipitation (Kidd and Huffman, 2011), surface waters (Alsdorf et al., 2007), as well as terrestrial water storage changes using more recent gravity-based methods (Rodell and Famiglietti, 1999; Swenson et al., 2003). Leveraging the spatial coverage of satellite data, a number of research efforts have also taken advantage of extended temporal sequences of these observations to compile long-term global datasets (Miralles et al., 2011; Liu et al., 2011a; Beck et al., 2017). Such satellitederived products provide an independent means of examining hydrological system dynamics and response (McCabe et al., 2005; Brocca et al., 2014), and offer the opportunity for an assessment of trends and variability in water cycle components (Y. Zhang et al., 2016b; Kidd, 2001; Liu et al., 2012; Miralles et al., 2014).

Considering the multitude of discipline-specific papers detailing diverse remote sensing applications in hydrology that have been published over the last few decades ${ }^{1}$, it is apparent that Earth observations have played an undeniable role in advancing the state of hydrological science. However, while reviewing this role is instructive and important, our intent here lies principally in foreshadowing the emergent opportunities that more recent and near-future observational developments might have in advancing and redefining our understanding of the terrestrial system and its interlinked processes. To do this requires expanding our review beyond just space-based sensors, especially since satellite remote sensing represents just one aspect of EO. Indeed, some of the earliest attempts at mapping and monitoring the Earth surface were conducted from hot-air balloons, progressing to fixedwing planes and high-altitude reconnaissance aircraft such as Lockheed's U-2 "spy plane"; the geopolitical repercussions of which, when combined with the rejection of Eisenhower's "open-skies" initiative, precipitated a tactical shift to spacebased sensing, and ultimately to the space race. Interestingly, while EO developments have largely been defined by finer and finer spatio-temporal resolutions or an increasing num-

\footnotetext{
${ }^{1}$ A search on SCOPUS using the terms "remote sensing hydrology" returns over 4300 unique contributions (1 June 2017).
} 

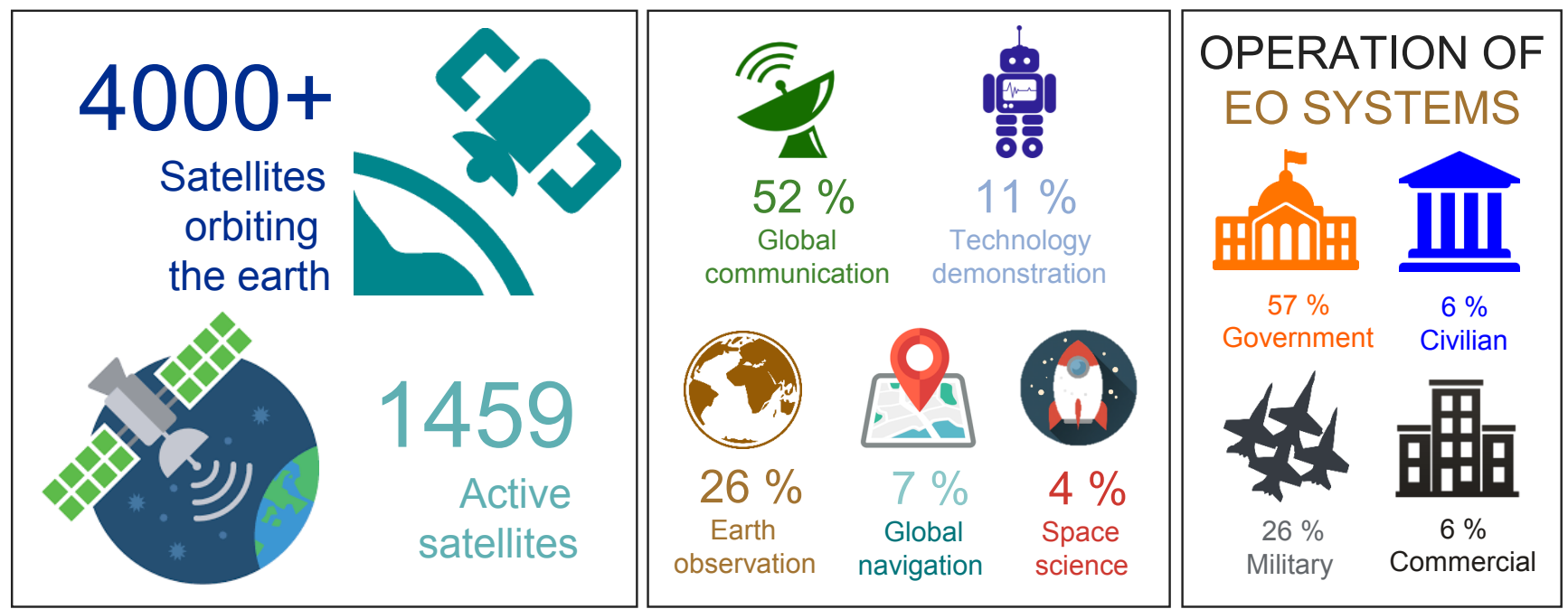

Figure 1. The state of play in space today. Estimates are based on the Union of Concerned Scientists satellite database, updated from 30 June 2016 (see http://www.ucsusa.org/nuclear-weapons/space-weapons/satellite-database). In terms of the sectors operating Earthobserving systems (right panel), another $5 \%$ include shared systems between those listed.

ber of resolvable bands, we are also witnessing something of a devolution in the choices available from our observing platforms. That is, some of the earliest approaches (balloons, fixed-wing aircraft, etc.) are being re-imagined through technological advances in system design, power management, autonomous operation, and the accuracy of navigational controls and communication infrastructure.

The overriding intent and purpose of this contribution is to introduce and explore some of these emergent technologies and observational approaches, highlighting new and innovative sensing platforms that are either still reaching maturity in terms of their application potential, or are yet to be fully embraced (or even recognized) by the larger user community. Another is to motivate some discussion on how we, as a scientific community, might better utilize available information and analytical resources, while also exploring the rapidly changing landscape of traditional space agencies in the light of recent commercial ventures in space-based observation. At the least, this research synthesis will present to the reader details on the ever-increasing number of observational tools and techniques that have the scope and potential to deliver new and powerful insights to our discipline.

\section{Overview of space-based Earth-observing systems}

The USA, European, Chinese, Japanese, Canadian, Indian, and other national space agencies operate a large number of satellite systems that deliver a diverse range of measurement types and/or spatial and temporal coverage to the science community. Including the International Space Station (ISS) and systems operated jointly between the USA and international agencies, NASA alone has 18 major Earth sci- ence missions currently in orbit, while the European Space Agency (ESA) has 11 EO missions in operation and a range of future satellites in advanced stages of planning and launch readiness. Other Earth-observing instruments from various international agencies operate on-board small satellites and CubeSats, as well as being mounted within the ISS. The petabytes of data gathered by these missions have supported tens of thousands of scientific investigations, practical applications, and breakthroughs in our understanding of the planet. There have been launch and instrument failures along the way, but the vast majority of large space agency missions have met their baseline objectives. There are many examples of successful joint international missions that have reduced the costs and risks associated with launching a satellite to the contributing countries, while increasing collaboration and data uptake. Unfortunately, attempts to coordinate multiplatform-observing systems in recognition of shared goals (e.g. holistic water cycle measurement) have been less effective: although NASA's A-train may serve as a partial counter example to this claim (Stephens et al., 2002). Obstacles to greater cooperation generally include scientific competitiveness, technological secrecy and political considerations, differing visions and needs, and the lack of an authoritative coordinating organization. All this is to say that there remain considerable challenges and barriers to overcome before an holistic and collaborative EO strategy can be realized.

While EO in all its forms is the focus of this synthesis paper, it is worth reviewing the somewhat narrower perspective of satellite-based remote sensing, given its central role in delivering hydrological observations. As detailed in Fig. 1, the last few decades have seen the launch of thousands of satellites, with over 4000 placed into orbit during this time. Of these, nearly 1460 are operational, with the largest pro- 
portion comprising systems that form the backbone of the global communication network. Earth-observing satellites, which include those operated by government, military, civilian, and commercial sectors, comprise around $25 \%$ of the operational satellites in space, representing some 360 unique platforms. While national governments operate the majority of the EO-based systems (57\%), recent years have seen an increasing number of both commercial and civilian platforms being launched: a trend that is expected to continue into the future (see Sect. 4).

\subsection{Problems, challenges, and knowledge gaps}

The past 25 years have seen astonishing advances in our ability to observe hydrological phenomena, driven in part by the maturation of satellite remote sensing, surging computing power, and data-storage capacity (Lettenmaier et al., 2015). Global measurements of rainfall, soil moisture, snow cover, groundwater storage change, surface water elevation, and other water cycle variables could scarcely have been imagined when the race to space began in 1957, and the innovators and agencies, who shepherded these developments deserve to be commended. Nevertheless, as detailed in Table 1 and discussed throughout this section, there remain critical gaps in our hydrological measurement and analysis capabilities. Snowfall, snow water equivalent, evaporation, deep soil moisture, groundwater depth and storage, water consumption, and water quality remain elusive targets, despite hopes that satellite missions to be recommended by the 2017 edition of the US Decadal Survey for Earth Science and Applications from Space (see http://sites.nationalacademies. org/DEPS/esas2017/) may address some of these retrieval challenges. As is proposed herein, continuous, holistic water budget observation would be superior to the current paradigm of asynchronous measurement of individual variables. However, apart from requiring a paradigm shift in how we undertake much of our research, achieving this also requires a breakthrough in observation cost efficiency, such as cheap, reusable rockets, or some other game-changing innovation. In Sect. 3, we explore some of these shortcomings and suggest improvements, highlight existing opportunities and identify some new innovations that may be on the EO horizon.

To date, only a handful of terrestrial hydrology-focused EO missions have been designed and launched by national and international space agencies. These were enabled by a shift towards more user-oriented missions over the last 2 decades, which allowed scientists to press for their data needs and helped steer missions from their earliest design (Lettenmaier et al., 2015). As a result of this engagement, there has been an increase in the range of hydrological variables that can be retrieved from space, spanning far beyond the snow cover extent, land cover, and topographic products of early satellite remote sensing research. Key elements of catchment- and continental-scale water balances are now routinely derived from the available suite of EO satellites. While this unprecedented wealth of data has brought about major advances in the study of large-scale hydrology, there remain gaps that need to be filled to increase our understanding of the hydrosphere, as well as issues that need to be addressed to ensure continued progress in our system knowledge. Here we detail some of these, with the aim of providing context and motivation for many of the new techniques and observation platforms on the EO horizon:

1. Satellite retrieval and interpretation challenges: a fundamental challenge in EO are the limitations imposed by only measuring the spectral signature of solar, Earth emitted, and reflected radiation, and using this information to retrieve a desired geophysical parameter (GRACE being an exception to this description). This issue can be extended to a perception in the literature that geophysical variables are directly obtained from EO, whereas the reality is that complex retrieval models, with their various simplifications, parameterizations, and non-unique solutions, are almost always employed to transform the satellite measurement into a specific variable of interest. For some variables, this conversion is quite straightforward (e.g. Normalized Difference Vegetation Index, NDVI), while for others, the retrieval model may have underlying assumptions or require ancillary data that contribute significantly to retrieval error (e.g. soil moisture, evaporation). Bearing in mind that the utility of Earth observations lay not just in their capacity to reveal insights on the hydrological cycle, but also in their potential to benchmark the climate models that we use to project hydrological response, an important issue emerges when one considers the dependency of EO datasets on their underlying models. In some cases, climate models and the retrievals against which they are benchmarked may share model assumptions and/or ancillary data. This interdependency can extend to the use of model climatologies or reanalysis forcing data in the generation of EO-based datasets (Mueller et al., 2013; Liu et al., 2011b). Given that "independent" satellite observations increasingly serve as indicators of climate change, or are used to detect trends in hydrological processes (see following point), it becomes critically important that a complete understanding, description and accounting of both the model and component forcing that underlie the production of EO data is provided.

2. Data homogeneity and harmonization: the capacity to develop long-term remotely sensed hydrologic records has proven useful across a range of applications, including (a) studying trends in the terrestrial water cycle (Miralles et al., 2014), (b) improving simulations of hydrological, eco-physiological, and biogeochemical models (Beck et al., 2017), (c) examining the social science implications of water availability (Müller et al., 2016), and 
Table 1. Hydrological variables and the current and planned satellite remote sensing missions that can be used to estimate them. We note that this list is not necessarily comprehensive and that there are possible trade-offs between resolution and accuracy that are not explicitly accounted for.

\begin{tabular}{|c|c|c|c|c|c|}
\hline $\begin{array}{l}\text { Hydrological } \\
\text { variable }\end{array}$ & $\begin{array}{l}\text { Missions/ } \\
\text { instruments }\end{array}$ & $\begin{array}{l}\text { Standard } \\
\text { spatial } \\
\text { resolution } \\
(\mathrm{km})\end{array}$ & $\begin{array}{l}\text { Standard } \\
\text { temporal } \\
\text { resolution } \\
\text { (days) }\end{array}$ & $\begin{array}{l}\text { Launch } \\
\text { year }\end{array}$ & $\begin{array}{c}\text { Dedicated } \\
\text { measurement }\end{array}$ \\
\hline Rainfall & GPM & 5 & 0.125 & 2014 & $\mathrm{Y}$ \\
\hline Snowfall & GPM & 5 & 0.125 & 2014 & $\mathrm{~N}$ \\
\hline \multirow{5}{*}{ Evaporation } & Terra/MODIS & \multirow{5}{*}{0.5} & \multirow{5}{*}{1} & 1999 & \multirow{5}{*}{$\mathrm{N}$} \\
\hline & Aqua/MODIS & & & 2002 & \\
\hline & Suomi/VIIRS & & & 2013 & \\
\hline & Landsat 8 & & & 2013 & \\
\hline & Landsat 9 & & & 2023 & \\
\hline Runoff & SWOT & 0.1 & 11 & 2021 & $\mathrm{Y}$ \\
\hline \multirow{3}{*}{ Snow cover } & Terra/MODIS & \multirow{3}{*}{0.5} & \multirow{3}{*}{1} & 1999 & \multirow{3}{*}{$\mathrm{Y}$} \\
\hline & Aqua/MODIS & & & 2002 & \\
\hline & Suomi/VIIRS & & & 2013 & \\
\hline $\begin{array}{l}\text { Snow density, depth, or } \\
\text { water equivalent }\end{array}$ & GCOM-W/AMSR2 & 30 & 1 & 2012 & $\mathrm{~N}$ \\
\hline \multirow{6}{*}{ Surface soil moisture } & SMOS & 36 & 3 & 2009 & $\mathrm{Y}$ \\
\hline & SMAP (radiometer) & 36 & 3 & 2015 & $\mathrm{Y}$ \\
\hline & ASCAT & 25 & 1 & 2006 & $\mathrm{~N}$ \\
\hline & GCOM-W/AMSR2 & 50 & 1 & 2012 & $\mathrm{~N}$ \\
\hline & Sentinel-1A & \multirow{2}{*}{$0.1-0.005$} & \multirow{2}{*}{12} & 2014 & $\mathrm{~N}$ \\
\hline & Sentinel-1B & & & 2016 & $\mathrm{~N}$ \\
\hline Deep soil moisture & Biomass & 0.2 & $18{\text { days } \mathrm{yr}^{-1}}^{-1}$ & 2021 & $\mathrm{~N}$ \\
\hline \multirow{4}{*}{ Surface water elevation } & Jason-3 & 10 & 10 & 2016 & $\mathrm{~N}$ \\
\hline & SARAL & 10 & 35 & 2013 & $\mathrm{~N}$ \\
\hline & SWOT & 0.1 & 11 & 2021 & $\mathrm{Y}$ \\
\hline & ICESat-2 & 1.5 & 90 & 2018 & $\mathrm{~N}$ \\
\hline Depth to groundwater & - & - & - & - & - \\
\hline Total groundwater storage & - & - & - & - & - \\
\hline \multirow{2}{*}{$\begin{array}{l}\text { Terrestrial water } \\
\text { storage change }\end{array}$} & GRACE & 220 & 30 & 2002 & $\mathrm{Y}$ \\
\hline & GRACE-FO & 180 & 30 & 2017 & $\mathrm{Y}$ \\
\hline Water consumption & - & - & - & - & - \\
\hline Water quality & - & - & - & - & - \\
\hline \multirow{8}{*}{$\begin{array}{l}\text { Vegetation/land cover/ } \\
\text { irrigated area }\end{array}$} & Terra/MODIS & \multirow{3}{*}{0.5} & \multirow{3}{*}{1} & 1999 & \multirow{3}{*}{ Y } \\
\hline & Aqua/MODIS & & & 2002 & \\
\hline & Suomi/VIIRS & & & 2013 & \\
\hline & $\begin{array}{l}\text { Landsat } 8 \\
\text { Landsat } 9\end{array}$ & 0.03 & 16 & $\begin{array}{l}2013 \\
2023\end{array}$ & $\mathrm{Y}$ \\
\hline & Sentinel-2A & 0.02 & 10 & 2015 & $\mathrm{Y}$ \\
\hline & Sentinel-2B & 0.02 & 10 & 2017 & $\mathrm{Y}$ \\
\hline & Sentinel-3A & 0.3 & 2 & 2016 & $\mathrm{Y}$ \\
\hline & Proba-V & 0.35 & 2 & 2013 & $\mathrm{Y}$ \\
\hline Vegetation stress & ISS/ECOSTRESS & 0.07 & 4 & 2018 & Y \\
\hline Photosynthesis & FLEX & 0.3 & 0.5 & 2022 & $\mathrm{Y}$ \\
\hline Water vapour & Aqua/AIRS & 13.5 & 1 & 2002 & $\mathrm{~N}$ \\
\hline Integrated water budget & - & - & - & - & - \\
\hline
\end{tabular}


(d) benchmarking the hydrology in land-surface and atmospheric models (Mueller et al., 2013), amongst numerous other examples. The development of long-term records demands the continuity (although, not necessarily replication) of previous successful missions, which for space agencies with static budgets, may come at the expense of more innovative exploratory missions. In addition, given the limited lifetime of satellite missions, these long-term records can only be achieved by merging datasets based on various sensors. As a consequence of this merging, observed inter-annual fluctuations may reflect discontinuities in the constellation of satellites, rather than actual hydro-climatological signatures (Liu et al., 2012). Efforts to harmonize satellite data represent a critical need, not just for more effective data assimilation or direct use of Earth observations in hydrological models, but to better understand any underlying physical process. To support such efforts, information on the accuracy of hydrological retrievals is required, which requires a departure from simple sensor precision and ground validation statistics, towards more appropriate error analysis and statistical equivalence that may reflect the artefacts of multi-sensor merging strategies (Su et al., 2016).

3. Engineering and operational constraints: if a satellite is to rotate around the Earth at the same speed that the Earth rotates around its axis, then it must be placed above the Equator in a geostationary position, approximately $35786 \mathrm{~km}$ above mean sea level. At that altitude, and with current technologies, visible and NIR frequencies can be measured at high temporal resolutions (min), but only at spatial scales of the order of kilometres (GOES-16 and Himawari- 8 can be tasked to capture sub-areas of a full disk at a frequency of $30 \mathrm{~s}$ ). Lower-altitude $(\sim 700 \mathrm{~km})$ satellites generally operate in polar orbits, allowing them to image a large part of the Earth surface, but at a coarser revisit time of one to several days. Such orbital limitations impede the ability to observe fast weather and hydrologic processes over the diurnal cycle at the needed high spatial resolutions (sub- to tens of metres). One way to leverage the higherresolutions achievable from lower-orbits and overcome the temporal repetition (cadence) issue is through the use of more than one satellite, i.e. constellations; a topic that is explored further in Sect. 3.4. Related in part to the satellite orbital characteristics, sensors and platforms are often poorly designed to provide data over regions where hydrological observations are the scarcest and most needed (e.g. tropics, poles, mountainous regions and urban areas), which limits the potential to close the hydrological balance at continental scales and advance our understanding of these processes. Finally, many hydrological variables require observations in the microwave portion of the spectrum (from Earth emit- ted radiation), but current technology limits antenna size and therefore spatial resolution (excepting synthetic aperture radar) and impedes the mounting of microwave sensors in geostationary satellites. Increased spatial resolution is necessary to help disentangle Earth emissions from heterogeneous land and atmospheric conditions (cloud and moisture variability, wet and dry surface areas, different vegetation classes, effects of topography, etc.). Optimizing the desired spatio-temporal combination against the physics-based constraints of orbiting systems is one area where emerging EO technologies (see Sect. 3) may offer a solution.

4. The need for comprehensive sensing: a number of unsuccessful missions (e.g. OCO, Glory, Landsat 6) have demonstrated the often capricious nature of space-based observation. Such mission failures (or instrument failures, as in the case of the Soil Moisture Active Passive (SMAP) radar) highlight that even with massive investment and allocation of resources to satellite programs, there is no guarantee of mission success, reflecting an inherent risk of single-instrument platforms. This third challenge relates to the scientific community's penchant to focus on using a single sensor to retrieve a single geophysical variable. Such "stove piping" of both science teams and retrieval algorithm development has impeded the progress of more comprehensive approaches to estimating global-scale hydrologic datasets. Indeed, there are numerous satellite systems that are currently in orbit, or in advanced stages of planning, which we seem ill-prepared to exploit (e.g. hyperspectral sensing), while at the same time, we rely on other sensors or variables that are often used well beyond the intent or purpose for which they were designed (e.g. NDVI). This may be a consequence of too much data, and too little cross-disciplinary interaction. Either way, the result is a plethora of variables that are being routinely collected by satellite systems, but which remain largely under-utilized by the community. As a manifest illustration of this issue, the current international Programs of Record includes over 700 existing or planned (approved) sensors for EO. It is more likely than not that most investigator or operational programs will use only a few of these. Rather than employing a piece-meal approach to EO, we require a comprehensive and consistent strategy that informs across a range of hydrological processes and responses.

5. The decline of evaluation infrastructure: finally, although the number of EO systems available for hydrological monitoring seem to be increasing, one of the most concerning aspects threatening the very foundation upon which much of our process understanding and conceptual developments derive, is the decline of in situ networks, especially since the 1980s (Fekete et 
al., 2012). Distinct from the issue of poor spatial representation of ground-based monitoring that discriminates collections in the developed versus developing nations, this is a negative trend that has been replicated across many regions of the world, from the USA (Lanfear and Hirsch, 1999) to the pan-Arctic (Shiklomanov et al., 2002). From a long-term monitoring perspective, one particularly worrying aspect of this decline is the demise of gauging stations (and other measurements) containing greater than 30 years of continuous records, which has been witnessed in the USA (see water.usgs.gov/nsip/history.html) and almost certainly seen in other parts of the world and for other hydrological variables (Lorenz and Kunstmann, 2012). Without long-term and well-maintained in situ networks, the challenges of disentangling the fingerprints of climate changes and its impact on hydrological systems becomes far more difficult (Hidalgo et al., 2009). While there have been encouraging activities that draw focus to the importance of in situ collections at catchment, regional, and even global scales (Zacharias et al., 2011; Dorigo et al., 2011; Stahl et al., 2010), sustained community effort is required. The importance of a robust and operational in situ network is an often underrecognized element of satellite research programs and initiatives. Indeed, it is not outrageous to posit that there are few conceptual advances or process insights resulting from space-based observations that have occurred independent of using ground-based monitoring. Technologies that strengthen and support this endeavour are immediately required.

To resolve many of these issues will require comprehensive programs that conceive EO as being based upon a variety of complementary platforms (i.e. satellite arrays that include nano-satellites, commercial aircraft-based sensors, long-deployment unmanned aerial vehicles (UAVs), highaltitude balloons, etc.; see Sect. 3), blended and merged with models in ways that are more informative than just using conventional data-assimilation approaches. The community has already developed hyper-resolution land-surface models that have been applied at $30 \mathrm{~m}$ scales over continental domains (Chaney et al., 2016), as well as approaches for integrating land-surface models with satellite retrievals to obtain time-consistent datasets (Coccia et al., 2015), or using diverse data to challenge hydrological simulations (Koch et al., 2015; Stisen et al., 2011). Other approaches beckon, especially the opportunities being facilitated by cloud-computing and data-analytic techniques (see Sect. 3.8). The emerging hyper-resolution trend (Wood et al., 2011; Bierkens et al., 2015) requires hyper-resolution forcing data, together with observations of the diurnal cycle of critical hydrological variables in order to prevent spatial and temporal inconsistencies between observations and models: a demand that we seem ill-prepared to meet.
To face these challenges, we have to recognize and accommodate the physics of EO, space agencies need to invest in new technologies (e.g. the development of nano-satellites and next-generation antenna) and ensure continuity of critical platforms, and they also need to support the community to develop improved retrieval models and encourage the use of measurements from a variety of sensors. All of this will require open and easily accessible data systems: something that to date has not been streamlined or optimized in the most efficient manner. What emerges from this brief summary is that it is not necessarily technological limitations that are inhibiting progress or advances. The challenges as listed seem largely scientific in nature, and reflect the need for a paradigm shift in how EO data are collected, disseminated, and utilized; a topic that is examined further in Sect. 3.

\subsection{Hydrology-specific data needs}

Some of the issues identified above are general to Earth observation as a discipline, rather than specific to the field of hydrology. For this reason, we shift the discussion to focus on some of the key data needs and knowledge gaps per water cycle variable. While the following is focused on satellitebased retrievals and does not explicitly detail other observation systems, the issues are not platform specific. In compiling this (deliberately concise) list, we perpetuate a previously recognized limitation of our community's approach to EO, i.e. the fixation on single-component retrieval, whereby we measure one water cycle variable at a time, and ignore the interdependencies and relationships inherent in observed responses (López et al., 2017). Here, by at least acknowledging the issue, we seek to excuse ourselves from perpetuating it.

- Precipitation: satellite retrieved rainfall was first inferred using visible and thermal infrared observations (Lethbridge, 1967), providing an estimate of rainfall volume (Kidd and Huffman, 2011). With the launch of microwave sensors such as the Advanced Microwave Sounding Unit-B (AMSU-B) and the Special Sensor Microwave Imager (SSMI), a shift towards more direct measurement was taken. Evolutions on these early missions are reflected in the dedicated Tropical Rainfall Measuring Mission (TRMM) and the latest Global Precipitation Mission (GPM), both of which use a combination of radiometers and high-resolution radar measurements. Precipitation is highly variable in both time and space, and therefore accurate representation demands a platform that reflects these spatio-temporal constraints. Unfortunately, while advances have been made, current capability still falls short in this regard. Microwave instruments on low Earth orbits limit repeat overpasses to once per day or longer. Although algorithms have incorporated infrared retrievals from geostationary satellites to fill the temporal gaps, these can introduce considerable uncertainty. Furthermore, measurement resolutions over land are typically greater than 
$5 \mathrm{~km} \times 5 \mathrm{~km}$, and are not anticipated to improve dramatically after GPM, presenting a further challenge for those seeking hyper-resolution hydrological modelling. Therefore, while remote sensing observations of precipitation have greatly improved our understanding of its global magnitude and variability, there remain critical knowledge gaps. Other long-standing issues include the detection of snowfall, drizzle, and extreme events (Rios Gaona et al., 2016) and the fact that lowerfrequency microwave channels often fail to discriminate between the scattering by ice in the clouds and that by the surface, while higher frequency channels require the extraction of the background emission, which is not trivial. An additional challenge is rainfall retrieval at higher latitudes, where snowfall is the largest contributor to annual precipitation, yet remains unsampled by the oblique orbits of TRMM or GPM. All of these issues are amplified by the disconnect between satellite data and traditional gauge-based measurements, which have well-recognized problems of poor distribution, wind-induced undercatch, elevation bias in gauge placement, and numerous other measurement complications (Lorenz and Kunstmann, 2012; Steiner et al., 1999). While ground-based polarimetric radars offer high temporal and spatial resolutions, they are only generally available in developed countries (Heistermann et al., 2013), have relatively poor coverage in mountainous areas, and their merging with satellite observations has often proven cumbersome (Lee et al., 2015). Nevertheless, due to their spatial and temporal continuity, ground radar data are considered the gold standard where they do exist. Further efforts to archive, harmonize, reprocess, and provide access to the global network of radar data are needed before the potential value of this data source can be fully realized ${ }^{2}$.

- Evaporation: monitoring the second largest flux in the continental hydrological cycle has proven to be especially challenging, whether from ground-based approaches or from space. A range of techniques to derive evaporation from remote sensing data exist (Anderson et al., 2004; Wang and Dickinson, 2012; Ershadi et al., 2014; Fisher et al., 2008; K. Zhang et al., 2016; Bastiaanssen et al., 1998). However, given the inability to observe this water flux in any direct way, all such approaches rely on rather complex empirical or process-based models, often requiring significant ancillary information and site-specific parameterizations. Moving forward, improvements are needed in both retrieval algorithms as well as satellite measurements. Large-scale satellite-based evaporation estimates generally have a resolution that is too coarse for critical applications such as drought assessment, water manage-

\footnotetext{
${ }^{2}$ See http://eumetnet.eu/activities/observations-programme/ current-activities/opera/ for an example of such an initiative
}

ment or agricultural monitoring, although there are regional to local-scale exceptions to this (Anderson et al., 2013; Cammalleri et al., 2014). To achieve the required high resolution over large spatial domains, equally highresolution observations of surface-level temperature and radiation budget components are required, together with improved representation of the hydrometeorology required to force many of these models (Ershadi et al., 2013). While current generation geostationary satellites can provide retrievals between 1 and $2 \mathrm{~km}$ in the visibleto-infrared spectrum, available global operational data products only offer coarse degree-scale resolutions, presenting a critical drawback for efforts targeting the production of global estimates (McCabe et al., 2016; Miralles et al., 2016). Finally, one of the key issues to advance the development of evaporation models is our representation of the vegetation components inherent in partitioning between evaporation and transpiration. The emergence of new remote sensing datasets (see Vegetation section below) that move beyond the relatively simplistic NDVI or leaf area index approaches that are currently employed, may provide a path forward to achieving needed model improvements.

- Soil moisture: over the years, several algorithms have been formulated to derive soil moisture from low microwave frequencies, resulting in numerous data products being developed since the late 1970s. These datasets have demonstrated their utility in hydrological applications at different scales, and have become a valuable tool for the climate community after merging into multi-decadal, multi-satellite, and multi-sensor (active and passive) records (Liu et al., 2012). With algorithm developments for active scatterometer-based retrievals (Naeimi et al., 2009) enabling soil moisture products from the Advanced Scatterometer (ASCAT) (Wagner et al., 2013), together with the launch of soilmoisture-dedicated missions such as the Soil Moisture and Oceans Salinity (SMOS) mission in 2009 and the SMAP mission in 2015, the retrieval of soil moisture from space has taken on a new dimension. Current research strives to improve the accuracy of retrieval algorithms (Mladenova et al., 2014), understand the spatial representativeness of the observations (Dorigo et al., 2015), increase the spatio-temporal resolution (Jha et al., 2013; Merlin et al., 2010), optimally ingest observations into hydrological models (Reichle et al., 2007), and explore the blending of different sensors (Liu et al., 2011b). The coarse resolution of passive-based retrievals remains a challenge, but advances in antenna technology may provide improvements on this. Shallow retrieval depths also limit the determination of root-zone moisture profiles and dynamics, although modelling approaches seek to improve deeper-soil representation (Das and Mohanty, 2006; Li et al., 2010). Despite the 
failure of the SMAP radar after only 3 months of operation, the performance of SMAP's passive retrievals has recently been evaluated with encouraging results (Pan et al., 2016). Likewise, the SMOS mission continues to provide valuable insights and an expanding range of derived products (Mecklenburg et al., 2016). Although no SMOS Follow-On mission is planned at this time, the future of satellite remote sensing of soil moisture remains bright, with the newly launched Sentinel-1 series from the ESA carrying high-resolution radars that have proven capabilities to deliver soil moisture at less than $1 \mathrm{~km}$ resolution and near-real time (Paloscia et al., 2013).

- Runoff: of all the hydrological variables, the one that typically draws the most attention from a water management perspective is river runoff. However, runoff is inherently local and difficult to determine from coarseresolution space observations. While some efforts have focused on using GRACE to derive long-term mean discharge for large rivers, most initiatives to date have been limited to running hydrological models of different complexities using satellite-derived digital elevation models, river height, inundation extent, or simply satellite-based precipitation. The long-awaited Surface Water and Ocean Topography (SWOT) mission (now planned for 2021) is set to measure surface water bodies and to infer river discharge. SWOT will carry a radar altimeter capable of deriving two-dimensional (2-D) images of surface water height, with a vertical accuracy of about $1 \mathrm{~cm}$ averaged over $1 \mathrm{~km}^{2}$ across a $120 \mathrm{~km}$ swath. This will deliver a substantial advance over previous altimeters used for hydrological applications that report only 1-D heights (Calmant and Seyler, 2006). However, while river height, width and slope will be derivable from SWOT, the calculation of river discharge will still rely on algorithms that account for the unknown channel depths and flow velocities. Any algorithm that has a requirement of in situ data for calibration limits its applicability in ungauged regions, where discharge measurements from space are the most needed. Moreover, estimates of discharge will correspond to the particular time of the SWOT overpass, which may not match the desired timing, especially in applications related to the detection and monitoring of flash floods that require both high spatial and temporal resolution.

- Groundwater and terrestrial water storage: gravimetric remote sensing represents one alternative to conventional electromagnetic sensing techniques for estimating water storage variables. Since 2002, GRACE has been measuring temporal anomalies in the Earth's gravity field, from which changes in terrestrial water storage (the sum of groundwater, soil moisture, surface water, snow, and biomass water content) can be inferred (Tapley et al., 2004). Combined with auxiliary model- or observation-based information, satellite gravimetry provides the only viable remote sensing approach for consistently estimating changes in groundwater storage (Rodell et al., 2007). However, GRACE's coarse spatial $\left(>150000 \mathrm{~km}^{2}\right.$ ) and temporal (monthly) resolution and data latency (typically 2-4 months) have limited its value for operational applications and decision-making, absent any model-based downscaling (Zaitchik et al., 2008). The GRACE Follow-On mission (to be launched in 2018) is expected to improve upon the retrievable resolution somewhat $\left(>100000 \mathrm{~km}^{2}\right)$. In spite of these limitations, the GRACE mission has proven to be one of the outstanding examples of non-traditional EO applications in hydrology, and serves as a reminder that process understanding is best achieved utilizing a range of complementary observation platforms.

- Vegetation: given the strong links between vegetation and multiple elements of the water cycle, there is understandable focus from the hydrological community on capturing plant response and dynamics at high spatial and temporal resolutions. Vegetation features are most clearly extracted from the VNIR, with sensors such as MODIS and Sentinel-2 providing unprecedented detail on plant-spectrum response. It could be argued that too much emphasis has been placed on relatively simplistic broadband-derived optical or near-infrared vegetation indices such as the NDVI, at the expense of other indices and portions of the electromagnetic spectrum (Houborg et al., 2015). For instance, microwave observations of vegetation optical depth (VOD) offer a close proxy of the water content and hydrological functioning of vegetation (Liu et al., 2011a, 2013), without the limitations of clear-sky conditions or the impacts of signal saturation in dense canopies and sun-sensor geometry issues. While research efforts have produced longterm records of VOD that hold considerable potential to improve understanding of land water fluxes and carbon storages (Liu et al., 2015), they are seldom employed in diagnostic studies of the hydrological cycle. In some ways, there seems to be a disconnect between the vegetation and water research communities that has led to the mis- or under-use of observable vegetation metrics. Solar-induced fluorescence (SIF) (Meroni et al., 2009) is one example of this disconnect. Observations of fluorescence by the Japanese Greenhouse gasesObserving SATellite (GOSAT) have mapped photosynthesis at the global scale (Frankenberg et al., 2011). Due to the synchronization of photosynthesis and transpiration through the stomatal conductance, SIF data could in principle be utilized to enhance our understanding of transpiration and evaporative stress (Alemohammad et al., 2016), but relatively little research has focused on examining this apparent link. Data from the Orbiting Carbon Observatory-2 (OCO-2) spectrometer, and 
the TROPOspheric Monitoring Instrument (TROPOMI) on-board Sentinel-5 Precursor (to be launched in 2017), will enable some of these ideas to be explored further, forerunning the first SIF-dedicated mission, the Fluorescence Explorer (FLEX) from the ESA (launch scheduled in 2022). While earlier SIF datasets had resolutions that were not particularly well suited for hydrological applications, OCO-2 and TROPOMI present improved spatial detail ( 3 and $8 \mathrm{~km}$, respectively), and in the case of TROPOMI, a near-daily revisit time.

- Snow and permafrost: terrestrial snow and frozen soils represent an important yet poorly represented component of the global water cycle. While the retrieval of 2D snow cover extent is a mature research field (Hall et al., 1995), the retrieval of snow depth, density, or water equivalent (SWE) is usually of greater interest to hydrologists, since these form key elements of model initialization and forecasting of runoff, drought and flood prediction (Bormann et al., 2013). Unfortunately, retrieving these and related cryospheric variables remains a major challenge, particularly for mountainous regions, where spatial variability is high and seasonal snow depth may reach tens of metres. Microwave sensors can be used for SWE and snow depth observations, but current systems lack optimal combinations of frequencies and resolutions. Although active microwave sensors can improve retrieval resolution and may be better suited for snow monitoring in mountainous regions, the maturity of active-based products has not reached the same level as passive approaches. However, even passive microwave-based SWE retrieval can suffer from signal saturation due to a deep snowpack, with commonly used $\mathrm{Ku}$ - and Ka-band microwave emission signals saturating at around $200 \mathrm{~mm}$ SWE. Given the importance of monitoring wet-snow properties for hydrology, synthetic aperture radar (SAR) retrieval approaches have been proposed, since passive approaches are not sensitive to dry snow parameters. Gravimetric techniques represent another alternative to microwavebased measurement of snow depth (Baur et al., 2009), but the approach is limited by the large spatial and coarse temporal characteristics of such sensors (Niu et al., 2007). In the light of the non-selection of ESA's $\mathrm{CoreH} 2 \mathrm{O}$ as an Earth Explore mission, there remains a need for high-resolution active microwave sensors with high revisit times to more effectively capture the dynamics of wet-snow in diverse terrain. Apart from snow covered surfaces, understanding the dynamics of frozen soils has become an increasingly important topic in hydrology, given the observed warming in many cold regions and the role that permafrost may play in changing river discharges, particularly in boreal areas (Woo et al., 2008). Permafrost properties include key state variables such as ground temperature, as well as thickness of the active layer, spatial patchiness and ice content. While there has yet to be a dedicated permafrost mission, EO data can be used to obtain permafrost-related features, such as the evolution in micro-topography, rock glaciers, thermokarst, and deformation. For instance, ESA's SMOS satellite has been used to detect the onset of soil freezing (Rautiainen et al., 2016) with encouraging results, while the SMAP mission would have provided key insights into permafrost processes, particularly the freeze/thaw state, which acts as a proxy for monitoring methane and carbon release (Heimann and Reichstein, 2008), forest productivity (Kimball et al., 2001), and sub-surface flow processes (Bayard et al., 2005). ESA's Sentinel 1 mission (Sabel et al., 2012), together with InSAR data (Liu et al., 2010), may present as possible platforms from which permafrost characteristics can be retrieved, advancing our knowledge of this increasingly important variable and our understanding of cold regions hydrology.

- Water vapour: a general drawback of current satellite observations for hydrological applications is their inability to provide vertical profiles of the atmospheric state with a high enough temporal resolution to allow for tracking of the fate and transport of water vapour. Water dynamics in the lower atmosphere are determined by complex interactions between the land surface and the free atmosphere, which are mediated by the diurnal cycle of the atmospheric boundary layer (ABL; from the surface to $2-5 \mathrm{~km}$ above). Diurnal processes like air entrainment into the ABL act as key drivers of evaporation, convective rainfall, or near-surface humidity. Therefore, understanding the connection between the surface and atmospheric branches of the hydrological cycle relies on adequately monitoring heat and moisture exchanges in the ABL over large spatial domains. However, this requirement demands the availability of temperature and humidity observations at fine time steps (e.g. hourly) and over high vertical and horizontal resolutions. Presently, low-orbiting sensors capable of providing vertical information, such as the lidar in the Cloud-Aerosol Lidar and Infrared Pathfinder Satellite Observation (CALIPSO), the radar in CloudSat, or the hyperspectral sounder in the Atmospheric Infrared Sounder (AIRS), can only provide data at daily (or much longer) temporal resolutions. Existing geostationary satellites, on the other hand, have frequent temporal sampling, but wider spectral bands and coarser vertical resolutions. Until these capacities are resolved in a single platform (or in a constellation of smaller satellite systems) the lack of any high spatio-temporal resolution data to monitor the evolution of the ABL will continue to constrain our ability to monitor diurnal cycles of atmospheric water fluxes from space. 
- Water quality: compared with other hydrology-related variables, relatively little focus has been directed towards characterizing inland surface water quality from space. Changes in the Earth's natural environment, whether from global warming, land use and land cover changes, or other anthropogenic causes, can significantly deteriorate freshwater quality (Whitehead et al., 2009). Given the limited availability of in situ water quality measurements, remotely sensed datasets offer a means to fill this knowledge gap, with temperature, suspended sediment, dissolved organic matter, and chlorophyll of particular interest. Lake and stream temperatures, which directly impact freshwater habitats, are very sensitive to climate changes (van Vliet et al., 2013). Although land-surface temperature products generated from sensors such as MODIS and Landsat are quite well developed, large-scale water temperature datasets are less common. Since estimating water temperature requires delineating water bodies, a MODIS-based water mask has been developed for this purpose (Carroll et al., 2009). However, resolving such information remains challenging for water bodies with surface areas that have large seasonal or inter-annual variations, or whose cross sections fall below retrievable resolutions. Suspended sediment and chlorophyll concentrations can be measured using VNIR data from Landsat, Sentinel-3, MODIS, and AVHRR, or with hyperspectral sensors (Brando and Dekker, 2003). Research on the use of physically based algorithms that monitor these properties is required, with high spatial and spectral resolution observations needed to advance such efforts (Odermatt et al., 2012). The Hyperion mission has contributed to sensing such variables with high accuracy (Giardino et al., 2007), but was decommissioned in lateFebruary 2017. With no dedicated water quality mission planned, there is interest in the proposed Plankton, Aerosol, Cloud, and ocean Ecosystem (PACE) satellite to advance terrestrial water quality monitoring (even though its primary focus is on oceans), but the future of this satellite remains uncertain in the light of the recent 2018 US budget announcement.

Section 2 has focused predominantly on our space-based observing platforms and identified some of the issues hindering developments in our characterization of the hydrological cycle. In order to drive continued advances in our system understanding, it is paramount that we exploit a comprehensive and holistic EO strategy, both with data that we currently have, as well as that which is only just emerging. To explore this concept and the opportunities being provided by a combination of new technologies, sensor innovations, and advanced analysis techniques, a presentation of some emerging monitoring systems and approaches that may leverage, support, or even supplant the traditional notion of EO is presented in the following section.

\section{Emergent platforms, capabilities, and technologies}

A few decades from now, historians may reflect on today's remote sensing capabilities the way we regard transportation in the early 20th century; i.e. most of the major modes were already in existence, but huge improvements in quality, cost and production efficiency, accessibility, and safety were yet to come. These improvements will be spawned and nurtured as before by government research investments, individual ingenuity, as well as private sector involvement. In this section we briefly summarize both the near- and mid-term plans of government space agencies and draw attention to a range of recent innovations that will augment and possibly disrupt the traditional concept of large orbital missions in the near, middle, and long term. Later, in Sect. 4, we review the commercialization of space, which will be essential in driving down orbital insertion costs and thus enabling the predicted efficiency and accessibility improvements for many of the technologies described below. In previewing some of these emergent observation platforms, Fig. 2 provides a concept of what a new Earth-observing "system of systems" might comprise.

\subsection{Future agency missions}

In forecasting the range of future hydrology-related satellite missions, it is not feasible to comprehensively list the entirety of national space agency plans in this brief overview. Realizing this, we use US agency missions as guidance for comparable space programs in Europe, China, Japan, and elsewhere. While the specifics might vary, there are some generalities that remain true. For example, space agencies typically discuss plans for their flagship Earth-observing missions 1015 years out, accept proposals and approve the formulation and science definition teams for missions 5-10-years out, and begin assembly $3-5$-years out. While NASA Venture class and smaller missions as well as bolt-on instruments typically have more compressed timelines, it is clear that the time horizons from mission concept to launch are long, rather than short.

Some hydrology relevant flagship missions currently approved and in various stages of development include the GRACE Follow On, Water Cycle Observation Mission (WCOM), SWOT, and ICESat-2. The joint NASA and German Aerospace Center (DLR) GRACE Follow-On mission, with a launch window between December 2017 and February 2018, will extend the unique monthly record of terrestrial water storage anomaly observations that have been provided by GRACE since 2002 (Tapley et al., 2004). In addition to the K-band microwave ranging system used to measure changes in distance between its twin satellites with extreme precision, GRACE Follow-On will use an experimental laser ranging system and design improvements that together are expected to increase the spatial resolution from roughly 150000 to $100000 \mathrm{~km}^{2}$ at mid-latitudes. China's WCOM, targeted for launch around 2020, aims to measure 


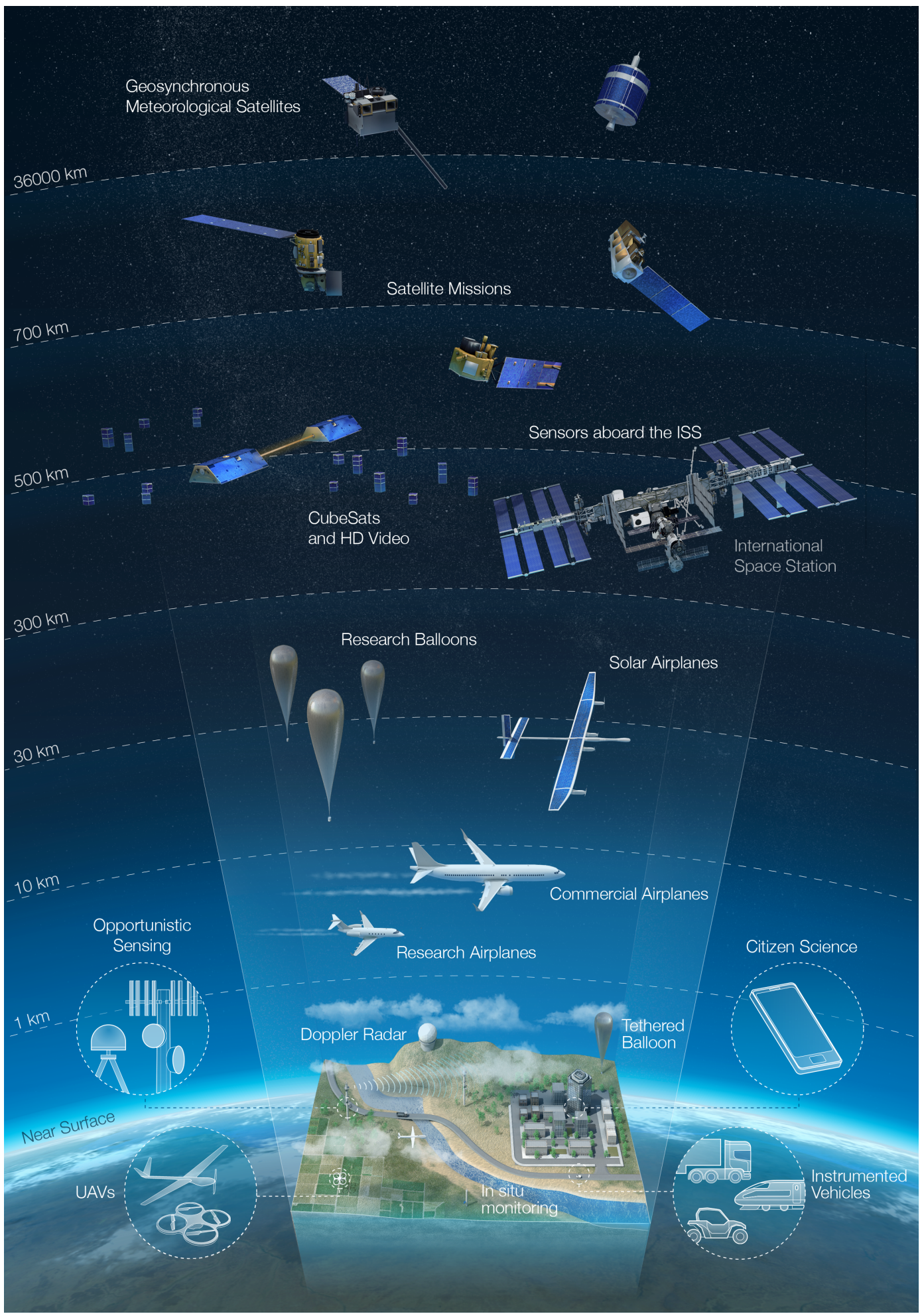

Figure 2. An Earth-observing "system of systems" for revolutionizing our understanding of the hydrological cycle. This multi-scale, multiresolution observation strategy is not really a concept, as the technology exists and is largely in place now. Supporting traditional space-based satellites, there are now a range of orbital options from commercial CubeSats to demonstration sensors on-board the International Space Station. Beyond orbiting EO systems, technological advances in hardware design and communications are opening the skies to stratospheric balloons and solar planes, as well as an explosion of UAV-type platforms for enhanced sensing. At the ground level, the ubiquity of mobile devices are expanding traditional in situ network capacity, while proximal sensing and signals of opportunity are opening up novel measurement strategies. 
soil moisture, snow water equivalent, soil freeze-thaw, atmospheric water vapour, and precipitation, amongst other variables. This is to be accomplished through accurate, simultaneous active and passive microwave measurements across a wide frequency range, obtained by three on-board instruments: (1) an L-S-C tri-frequency interferometric microwave imager with $15-50 \mathrm{~km}$ spatial resolution, consisting of a $9 \mathrm{~m} \times 6 \mathrm{~m}$ mesh reflector and a 1-D thinned array as the feed, (2) a polarized microwave imager covering 7.2 to $90 \mathrm{GHz}$ with a $1.8 \mathrm{~m}$ diameter reflector antenna for conical scan, and (3) an X-Ku dual-frequency polarized scatterometer with 2$5 \mathrm{~km}$ spatial resolution and $1000 \mathrm{~km}$ swath for snow water equivalent and freeze-thaw mapping. NASA's SWOT mission, scheduled for launch in 2021, will return accurate surface water elevations over $90 \%$ of the globe at least twice every 3 weeks, enabling estimation of river runoff as well as surface water storage. SWOT will employ a wide swath, Ka-band radar interferometer to resolve $100 \mathrm{~m}$ wide rivers and $250 \mathrm{~m}^{2}$ lakes, wetlands, or reservoirs with a height accuracy of $10 \mathrm{~cm}$ and a slope accuracy of $1 \mathrm{~cm} \mathrm{~km}^{-1}$. Recent runoff data are currently available from only a fraction of the world's rivers, due mainly to closed data policies outside of a few developed nations. SWOT will fill a major void in our observational capabilities. NASA's ICESat-2, while primarily focused on precise laser altimetry for ice sheet mapping, will also prove valuable for monitoring surface water elevations (Jasinski et al., 2016), particularly before the launch of SWOT. Other missions, such as NOAA's Suomi National Polar-orbiting Partnership (Suomi NPP; launched in 2011) Joint Polar Satellite System 1 (JPSS-1; scheduled for launch near the end of 2017), and future missions in the JPSS series are mainly geared towards atmospheric measurements, but all will carry Visible Infrared Imaging Radiometer Suite (VIIRS) instruments, which collect visible and infrared imagery useful for monitoring snow cover and vegetation as an input to retrieval algorithms for numerous hydrological variables. ESA's Sentinel-4 Earth-observing mission (planned for launch in 2019) and its Sentinel-5 successor, will focus on air quality monitoring. ESA also plans two Earth Explorer missions related to hydrology: (1) the Biomass mission (planned for launch in 2021) will carry a P-band SAR for the purpose of estimating forest biomass, but which may also be useful for inferring root-zone soil moisture; and (2) the FLEX mission, which will map vegetation fluorescence to quantify photosynthetic activity and should help to constrain transpiration rates. In addition to these large missions, NASA's Venture class ECOsystem Spaceborne Thermal Radiometer Experiment on Space Station (ECOSTRESS) (scheduled to be deployed aboard the ISS in 2018), will measure vegetation temperatures with the aim of constraining transpiration estimates and better understanding plant response to stress.

The 2017 edition of the Decadal Survey in Earth Sciences is intended to guide the prioritization and selection of major US Earth-observing satellites for the next 10 years. While the 2007 edition (National Research Council, 2007) recommended specific mission architectures, the new edition is expected to recommend observables and to leave mission and instrument design to the agencies and proposing institutions. At the time of writing, it is unknown what hydrological observables will be prioritized, but based on the missions that were included in 2007 (but did not enter NASA's mission queue due to a second or third tier ranking), we speculate that snow water equivalent will be a priority. Referring to Table 1 , evaporation is another variable that may be targeted due to its importance, lack of a current, dedicated mission, and existence of a demonstrated retrieval approach. Deep soil moisture could also be on the list, although soil moisture algorithms that make use of wavelengths longer than L-band (e.g. P-band at $40 \mathrm{~cm}$ ) are not yet mature (Moghaddam et al., 2007).

While there are impressive and innovative sensing platforms scheduled for launch in the next 5-10 years (or in advanced stages of planning) across international space and government agencies, there are emerging parallel opportunities for both investigator-driven and commercially-led activities that have the potential to reshape the EO landscape in hydrology. A selection of these are explored below.

\subsection{Unmanned aerial vehicles}

One of the most exciting recent advances in near-Earth observation lies in the field of unmanned aerial vehicles (UAVs), also referred to as "unmanned aircraft systems" or "remotely piloted aircraft systems". Often used interchangeably, or simply referred to as a drone, the terms encompass the remote or semi-autonomous operation of an airborne vehicle. In a way, these new observation platforms represent a "hook in the sky" from which to deploy a range of sensors. The application of UAVs for remote sensing has offered new opportunities to map, monitor, and understand the environment in unprecedented detail (Anderson and Gaston, 2013), particularly at the scale at which traditional field-based observations can be made, but also covering a greater spatial extent with a unique top-down view (see Fig. 3). The key advantages of UAV-based remote sensing is their capacity to (1) collect ultra-fine resolution imagery (defined here as $1-20 \mathrm{~cm}$ pixel size); (2) acquire data on-demand at critical times and with high temporal resolution at costs affordable to an individual investigator; (3) carry multiple sensors (both active and passive) across the electromagnetic spectrum; (4) be employed for calibration and validation of satellite products; (5) complement, extend, or potentially replace field surveys (especially in areas that are difficult to access); and (6) provide a scaling tool between field and satellite data. Most importantly, this rapidly emerging technology offers the opportunity to reveal new insights into hydrological, geomorphological, atmospheric, and biotic processes, and represents a game-changing sensing platform. 

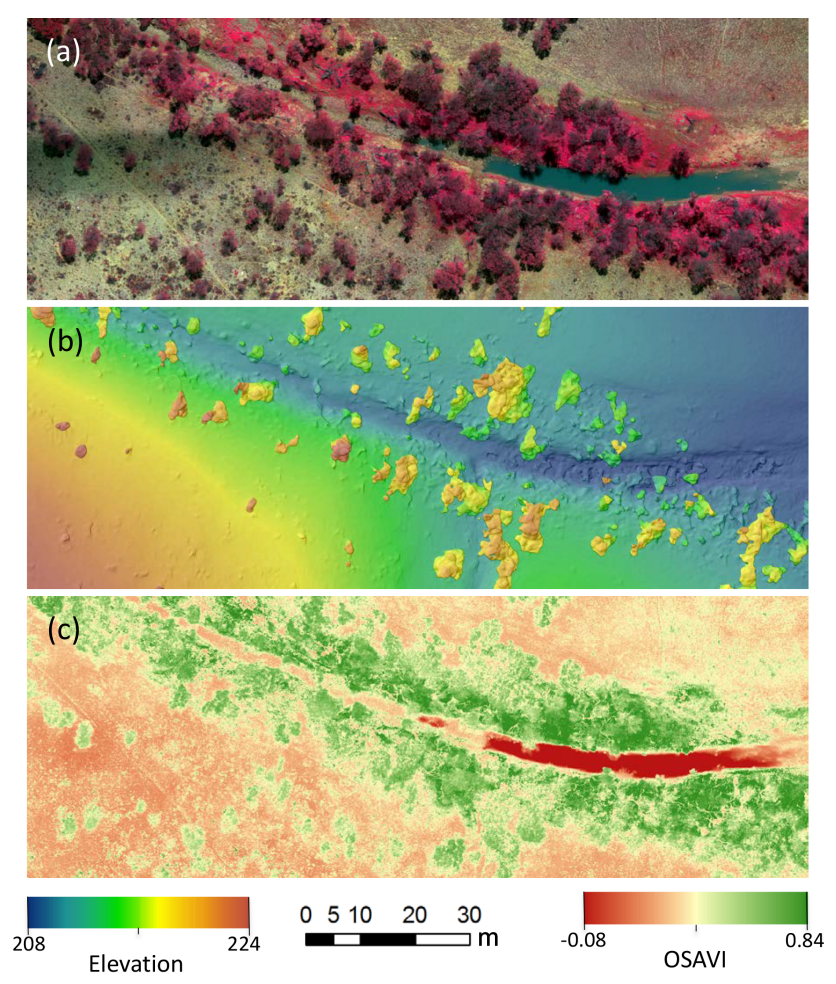

Figure 3. Employing a UAV to retrieve high-resolution multispectral information on the land surface for hydrology and related applications over an Australian rangeland site located near Fowler's Gap in New South Wales. Retrieved products include (a) a false-colour infrared image, (b) a reconstructed digital surface model using visible imagery and structure-from-motion techniques and (c) an optimized soil adjusted vegetation index (OSAVI) derived from the 4-band multispectral image. Images were captured using a MicaSense/Parrot Sequoia sensor on-board a 3DR Solo quadcopter. The UAV was flying at a height of $40 \mathrm{~m}$, providing a ground sampling distance of approximately $3 \mathrm{~cm}$. Imagery provided by the University of Tasmania's TerraLuma Research Group.

In a recent contribution, Vivoni et al. (2014) reviewed the application of UAVs for eco-hydrology and suggested that UAV remote sensing can fundamentally change how ecohydrologic science is conducted. This same is true for hydrology. At the most basic level, UAVs can provide turn-key solutions of ultra-high resolution RGB imagery using consumergrade cameras. Recently, multispectral and thermal sensors have gained traction and are increasingly being deployed by scientists. While lidar and hyperspectral sensors are still in an early operational phase, rapid progress is being made. One of the breakthrough technologies to the success of UAVs for mapping applications is structure-from-motion (SfM) and dense image matching (Turner et al., 2012). SfM is based on photogrammetric principles and generates detailed 3-D point clouds from overlapping and multi-view photography. UAV platforms are ideally suited to fly overlapping flight lines, and collect hundreds of images during dedicated campaigns. Using SfM approaches, extremely rich 3-D informa- tion on the terrain, vegetation, buildings, geology, etc. can be extracted cheaply and efficiently by the end user. For hydrological applications, SfM provides information on microtopography and can be used to generate digital terrain models (DTMs) and digital surface models (DSMs) at unprecedented detail. Apart from their natural affinity to application in precision agriculture (Zhang and Kovacs, 2012) and for vegetation health and stress monitoring (Zarco-Tejada et al., 2012, 2013), a number of recent contributions have demonstrated the utility of UAVs in hydrological process studies, with snow depth retrieval (Vander Jagt et al., 2015), flood mapping (Feng et al., 2015), irrigation monitoring (Bellvert et al., 2016), and evaporation estimation (Hoffmann et al., 2016) all being explored.

New UAV-based sensor technologies are likely to drive further advances in hydrological process description and understanding. For example, advances in sensor manufacturing have now enabled production of frame-based hyperspectral snapshot systems that are much smaller than a typical consumer-grade compact camera. Similar miniaturization processes are being applied to thermal sensors and laser scanners. These recent developments present opportunities to the hydrologic community by offering the combination of multiple sensors that acquire data simultaneously. The acquisition of 3-D information on terrain and vegetation, together with hyperspectral and thermal imagery, was previously a highly specialized task for very experienced airborne remote sensing crews. Now, this multi-sensor capability is already available for UAV platforms, providing unprecedented information for remote sensing applications. However, as with any new technology, UAV deployment comes with challenges as well as opportunities. One potential threat to the success of UAV remote sensing is that innovations are primarily driven from a technological rather than scientific perspective. While new airframes and sensors are evolving at an impressive pace, research is required to deliver rigorous processing workflows and to generate accurate and robust end products that are meaningful. There is a real risk that new sensors and products may produce little more than "pretty pictures" without a thorough understanding of sensor performance, precision and calibration. Semi-automated processing workflows are needed to ensure accurate geometric, radiometric, and spectral corrections. These workflows will have to cope with a data deluge of hundreds to thousands of images that typical flight campaigns generate, but developments in cloud computing (Sect. 3.8) may provide a solution to the currently long processing times. Furthermore, as the need (or desire) for ultra-high-resolution imagery increases, there will be a push to extend UAVs beyond visual line of sight (BVLOS) in order to cover larger areas. Visual line of sight is a current legal limitation of UAV operation in many countries, which effectively limits the size of the study area to an order of $1 \mathrm{~km}^{2}$, making the retrieval of information over larger catchments a laborious and time-consuming process. Improvements in technology and safety will ultimately make BVLOS opera- 
tions feasible, but it will take time for regulatory bodies to keep pace with advances in technology.

Even though UAV remote sensing requires expertise in piloting, sensor operations, calibrations, and image processing workflows, it is now possible for small groups and even individual end users to collect their own ultra-high-resolution multi-sensor EO data: a capability that even a decade ago, was the purview of space agencies and highly specialized airborne data providers. In the not too distant future, fully autonomous systems are anticipated. Although current applications are some way off being completely autonomous, the ultimate goal of the UAV is analogous to the image-capturing capability of the space-based satellite: a self-propelling, powered, self-contained, and independent data-collection system. So long as the needed developments in UAV science can keep pace with the rapid technological innovations, these innovative observation platforms are well placed to deliver needed advances in hydrological understanding.

\subsection{Stratospheric balloons and solar planes}

UAVs are not the only non-orbiting remote sensing systems driving progress in hydrological observation: they are just one of the latest. Aerial weather balloons have been used for more than a century to remotely monitor terrestrial systems. Some of the earliest uses of balloons were to carry observers over battlefields throughout the 1800s and even during World War I, providing an unparalleled logistical and military planning tool. Today, balloon designs enable a low-cost, stable platform for intriguing hydrologic and related remote sensing applications (Chen and Vierling, 2006). Apart from providing soundings of atmospheric temperature, pressure, and humidity, along with a variety of other meteorological variables, a range of enhanced measurement capabilities are also possible. Vierling et al. (2006) constructed a tethered balloon consisting of meteorological instruments, Global Positioning System (GPS) receiver, thermal infrared camera, and a video camera, all operating in real time with data downlinked to a receiving computer. A more recent and novel application was the use of a mobile laser scanning lidar attached to a tethered balloon to acquire topographic elevation measurements (Brooks et al., 2013; Hauser et al., 2016). Costing approximately USD 100000 , the approach yielded a point cloud of elevation measurements accurate to about $5 \mathrm{~cm}$ and spanning an approximately $75 \mathrm{~m}$ swath along the balloon's trajectory. Another system was developed by Shaw et al. (2012), who retrofitted a tethered balloon with red and infrared imaging capabilities for less than USD 1000, providing an approximately $12 \mathrm{~cm}$ spatial resolution in a $64 \mathrm{~m}$ wide imaging swath from a legally restricted flying height of $50 \mathrm{~m}$.

Like balloons, aircraft-based remote sensing has existed since the earliest developments of powered flight. Since more traditional aerial methods are well-known and easily accessible via the peer-reviewed literature (Green et al., 1998), we focus here instead on a more speculative but intrigu- ing sensing future. Consider the recent around-the-world piloted flight of the Solar Explorer 2 (2016), an entirely solarpowered aeroplane weighing $2300 \mathrm{~kg}$ and having a $72 \mathrm{~m}$ wingspan. Covered in more than 17000 photovoltaic solar cells, the craft achieved a maximum flight leg lasting almost 5 full days and nights. While this experimental system cost more than USD 200 million, it highlights the future possibilities of having unmanned aircraft flying uninterrupted over fixed locations, without the need for landing. Back of the envelope calculations, assuming an average velocity of $75 \mathrm{~km} \mathrm{~h}^{-1}$ and a maximum piloted altitude of $8500 \mathrm{~m}$, suggest that a similar unmanned plane equipped with an imaging sensor capable of $20 \mathrm{~km}$ swath widths could observe areas of $300 \mathrm{~km}$ by $120 \mathrm{~km}$ in a single day: enough to sense the extent of the Sierra Nevada and its snowpacks in about 3 days.

Unsurprisingly, improved Earth observation is not the only motivation driving the exploration of balloons and solarpowered platforms. A number of Silicon Valley technology companies have well-developed plans to use unmanned systems to deliver broadband internet coverage to poorly connected regions of the globe. Google's Project Loon (https://x. company/loon/) is perhaps the most advanced of these and is based on the idea of using stratospheric winds to navigate and control an interconnected network of high-altitude balloons. Using this approach, the project aims to provide internet access to both developed and developing communities. With a similar goal in mind, Facebook's Project Aquila (Zuckerberg, 2016) is a parallel effort exploring solar-powered aircraft. Aquila's aim is to have a fleet of planes flying at between 18000 and $27000 \mathrm{~m}$ that would stay aloft for months at a time, using on-board lasers to transmit and receive information to users below. A first unmanned flight was completed in late-June 2016, lasting for 96 min (Flying Aquila, 2016), but many technical barriers remain to be overcome. While these examples are focused on providing communications infrastructure to the estimated 2 billion people currently without internet access (representing an untapped revenue stream relative to the largely saturated market in most developed countries), there are clear opportunities for leveraging such systems for enhanced EO. Harnessing a fleet of highaltitude balloons or aircraft with an array of lightweight sensor packages provides a platform not just for opportunistic sensing, but also for evaluating new technology, calibration and validation of satellite systems, and supporting large-scale test beds for product assessment: the last representing an often ignored (or under-funded) element of space-based Earth observation. Leveraging the advances in technology behind the commercial development and production of these systems may provide scientists with direct access to their own airborne platforms, offering capabilities to individuals or research teams that are currently beyond the scope or reach of most. While such future platforms remain somewhat speculative, these early developments are not just exciting: they represent real pathways towards an enhanced Earth observation strategy. 


\subsection{The rise of the CubeSat}

The demand for increased spatial and temporal resolution is one of the underlying drivers of sensor and platform development, with the assumption being that enhanced resolution will improve the monitoring, characterization, and understanding of terrestrial ecosystems. Till recently, there has been a rather incremental improvement in observing system specifications. Current agency-based high spatial resolution satellites, such as the Landsat series or Sentinel-2 platforms, provide spatial detail at the $10-100 \mathrm{~m}$ resolution, but are constrained by the temporal frequency of acquisitions (5-16 days). When considering the influence of cloud cover on the visible, shortwave infrared, and thermal infrared portions of the spectrum, data continuity and availability can be severely impeded (Roy et al., 2008). While deploying two identical sensor systems, as with Sentinel-2A and -2B (Drusch et al., 2012), represents significant progress towards improving the temporal resolution, acquisition of near-daily high-resolution imagery can only currently be met via the expensive tasking of commercial multi-sensor satellite systems such as RapidEye and WorldView (Houborg et al., 2015), and only then on an area-limited basis.

One way in which enhancements in revisit time and large area availability can be realized is via the launch of a larger number of replicate sensor systems. In the past, such attempts have been hindered by the high mission costs of the type of large satellites favoured by space agency missions. For instance, Landsat- 8 (which is around the size of a large car), had an estimated cost of USD 855 million to build and launch, and therefore producing multiple versions (not including associated launch costs) is not a realistic proposition. The 2014-2020 budget for the European Copernicus Earth observation program, which includes the Sentinel missions, is estimated at approximately EUR 4.3 billion, but does not include multi-satellite constellations beyond the Sentinel-2 pair (Denis et al., 2016). Here the key limitation in the replication of multiple sensing platforms relates to the satellites size and the associated price tag. One possible solution to this constraint that has seen some impressive real-world results is an obvious one: make satellites smaller and lighter and they become cheaper to launch. Such an approach is behind the CubeSat concept, introduced by Stanford University and the California Polytechnic State University in 1999 (Puig-Suari et al., 2001). CubeSats have provided the foundation upon which the recent surge in the development and launch of constellations of compact (i.e. $0.1-10 \mathrm{~kg}$ ) pico- and nano-satellites (Bouwmeester and Guo, 2010; Selva and Krejci, 2012) can largely be attributed. A single-unit (1 U) CubeSat, measuring $10 \times 10 \times 11.35 \mathrm{~cm}^{3}$ and typically weighing less than $1.33 \mathrm{~kg}$, forms the base level building block for a range of larger configurations. Indeed, CubeSats can be configured in a variety of sizes, increasing as integer multiples such as 3, 6 or $12 \mathrm{U}$, to expand observation capacities and potential applications (Hevner et al., 2011). The advances driving CubeSats have not occurred in isolation, nor are they solely a product of economies of scale. The economics of space observation is changing rapidly, due to a combination of sensor miniaturization (allowing the development of standardized smaller satellites comprised of commercial off-theshelf - COTS - components) and their deployment as secondary payloads on commercial and public launch platforms (Woellert et al., 2011). The emergence of reusable rockets is also a major driver in the cost reduction of actually placing infrastructure in orbit, making the launch of investigatorled CubeSats a feasible proposition (see further details in Sect. 4.2).

Regardless of the driving forces behind their emergence, CubeSats represent a cost-effective observation strategy that provides a unique opportunity for the implementation and demonstration of technological innovations, serving as potential test beds for advanced visible-infrared sensing systems (to date, the power requirements of active sensors currently limit their integration) or even as direct replacements to larger satellite missions (see e.g. NASA's CubeSat Launch Initiative; NASA, 2016a and Small Spacecraft Technology Program; NASA, 2016b). NASA's Jet Propulsion Laboratory (JPL) is actively exploring the CubeSat potential, with new on-board processing and sensor technology testing being conducted on planned CubeSat missions (Edberg et al., 2016). From a hydrological perspective, JPL's RainCube (Haddad et al., 2016), which is scheduled for launch in 2017, will act as a demonstration mission for the use of Ka-band radar for precipitation retrieval. Another JPL project is the CubeSat Infrared Atmospheric Sounder (CIRAS), that seeks to match some of the temperature and water vapour profiling capabilities of the AIRS instrument (Aumann et al., 2003), but on a considerably smaller platform. Driving these efforts is the opportunity to leverage the significantly reduced cost, relative to conventional satellites, that makes launching constellations or swarms of CubeSats economically feasible. They also represent an inherent risk minimization strategy; a systems failure on a sole-satellite configuration is mission ending, while multiple failures could occur within a constellation and still retain its mission capability. Such an approach has the potential to revolutionize monitoring capacity from space, not just from a hydrological perspective but also across disciplines and sectors.

A number of commercial companies are leading the way in exploiting this observation strategy, most notably Planet (formerly known as Planet Labs; http://www.planet.com), who, with more than 1503 U CubeSats launched since 2013, manages the world's largest constellation of satellites in orbit (Planet Team, 2017). Planet's flock of "Doves" are capable of capturing RGB and near-infrared imagery at $3-5 \mathrm{~m}$ ground sampling distance (GSD), providing near-daily global coverage based on a full constellation of nano-satellites. This emerging resource provides new and exciting opportunities for a wide range of applications seeking to exploit high-resolution clear-sky imaging. One recent example using 


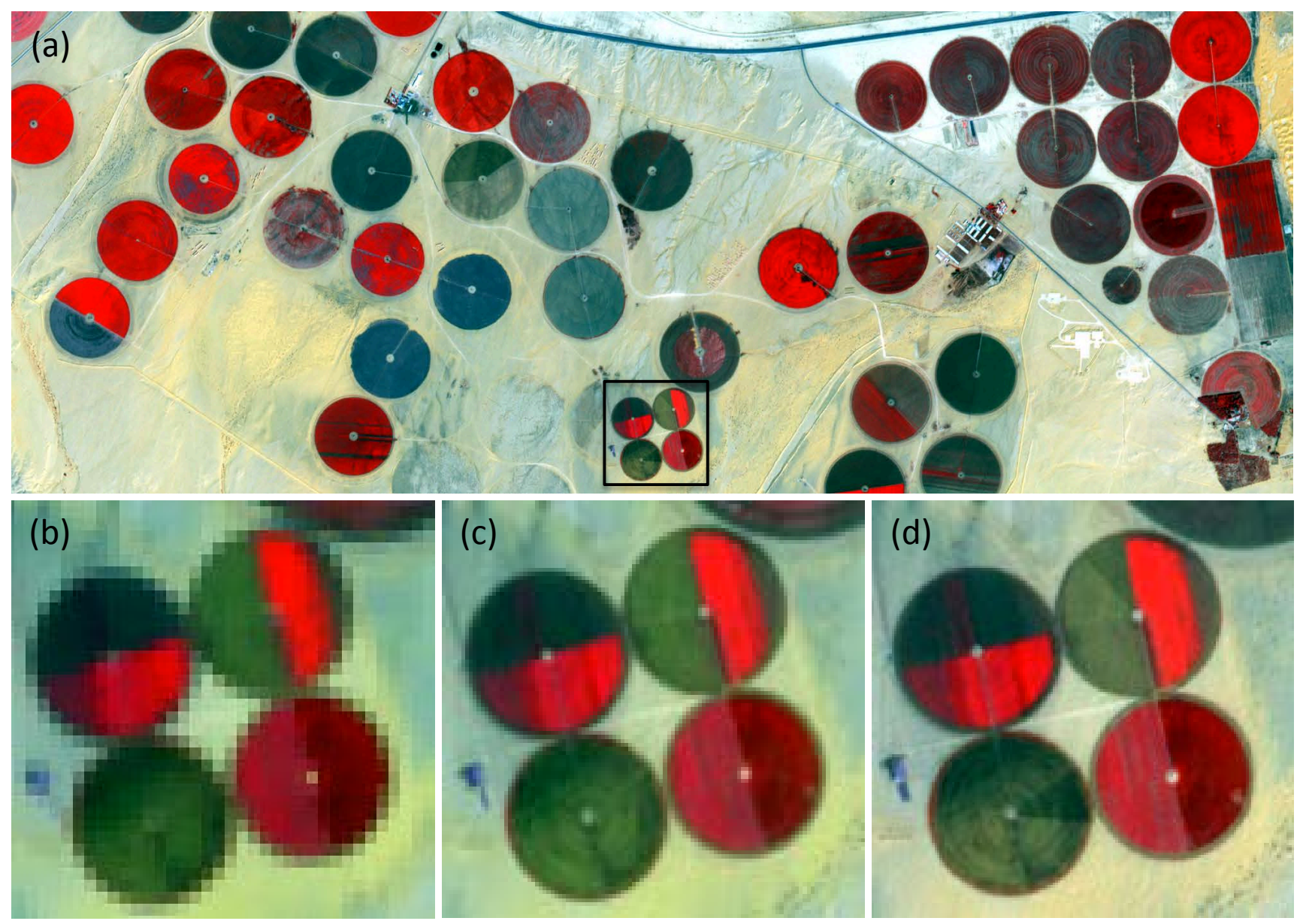

Figure 4. Multi-scale capabilities of state of the art sensing optical satellites. Image illustrates the expanding resolution options available from both commercial and government satellites. (a) Planet CubeSat at $3 \mathrm{~m}$ ground sampling distance over the Tawdeehiya Farm in Al Kharj, Saudi Arabia. Centre-pivot irrigated fields dot the landscape, with dimensions approaching $800 \mathrm{~m}$. The inset in (a) is zoomed to show the resolution advantages offered by the next generation of sensing solutions over (b) Landsat- 8 at $30 \mathrm{~m}$, with (c) Sentinel-2A at $10 \mathrm{~m}$ and (d) Planet imagery at $3 \mathrm{~m}$ providing enhanced details. All images are false colour representations of NIR, red and blue in RGB bands. Sentinel-2A and Landsat-8 images were acquired on 4 December 2016, while the Planet data were captured on 5 December 2016.

these data is the retrieval of high-resolution NDVI for precision agriculture (Houborg and McCabe, 2016), but there are clear applications in land cover and land use change detection, environmental monitoring and numerous other fields of interest (see Fig. 4). The CubeSat approach features in other commercial enterprises, such as the planned Astro Digital Landmapper high-definition constellation, which comprises $206 \mathrm{U}$ CubeSats capturing five spectral bands at a GSD of $2.5 \mathrm{~m}$ every 3-4 days (http://www.astrodigital.com). Likewise, Planetary Resources (http://www.planetaryresources. com) envisions a programmable constellation of $1012 \mathrm{U}$ CubeSats, delivering visible to near-infrared (400-900 nm) hyperspectral and mid-wave $(3-5 \mu \mathrm{m})$ thermal infrared data at 10-15 m GSD for any spot on Earth on a weekly basis. With the cost of a CubeSat ranging anywhere from a few tens of thousands upwards (including launch costs), the prospect of investigator or community-driven missions becomes a realistic proposition.

Instead of launching constellations (i.e. a large number) of independent satellites into space, others have advocated the concept of a dense network of distributed space missions working in cooperation, where sensing systems coordinate to achieve a monitoring task in much the same way as a distributed sensor network collects information on the ground (Barnhart et al., 2009). Using satellite-on-a-chip or printed circuit board approaches, such low-cost, sub-kilogram options have obvious potential for hydrological and related sensing. While the next generation of CubeSats has the potential to revolutionize Earth observation, data from such platforms should ideally complement, and not necessarily replace, the high-quality imagery that is currently acquired by conventional large satellite missions. To harness the potential and exploit these technological advances demands prepara- 


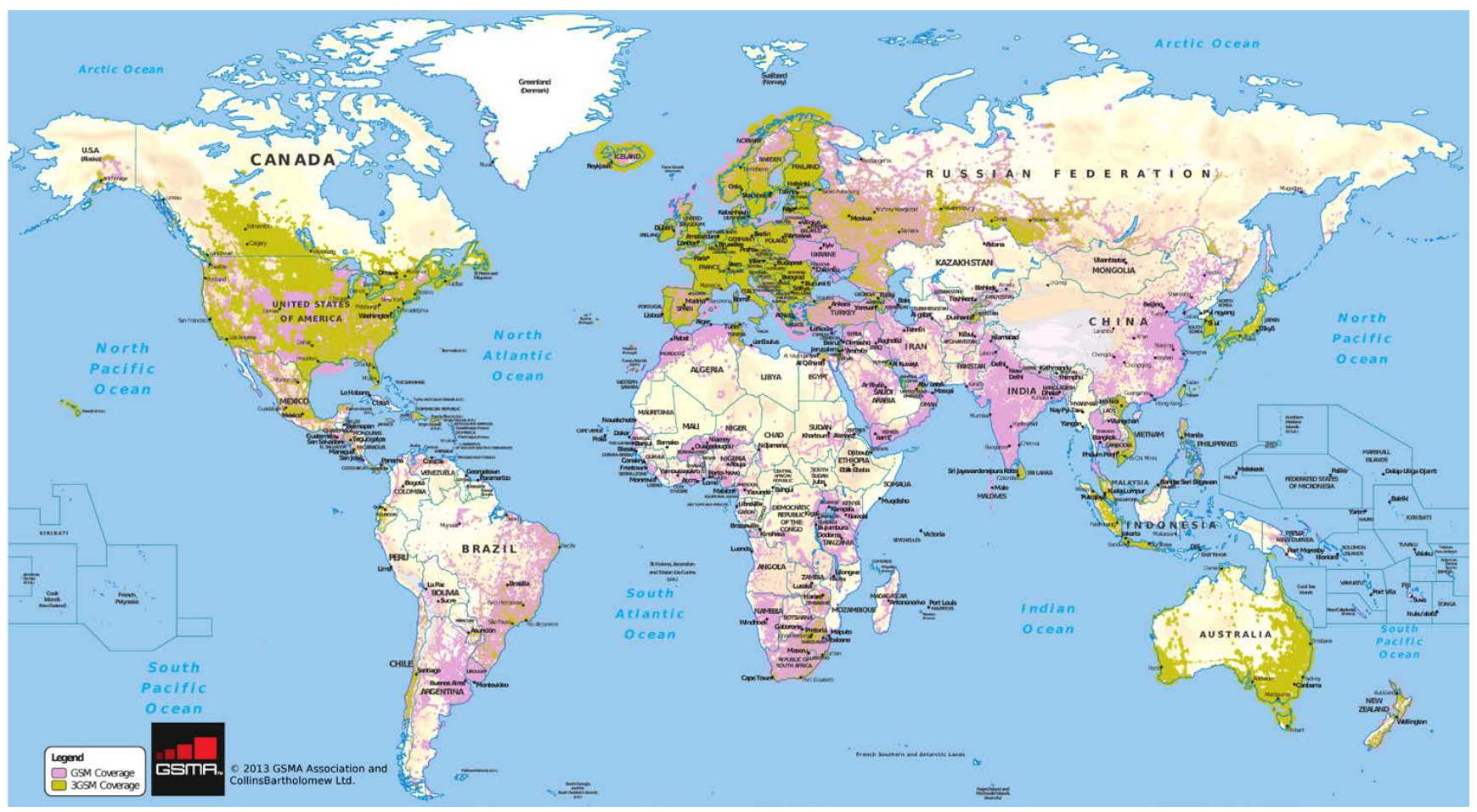

Figure 5. Worldwide global system for mobile communication (GSM) coverage for the year 2013. The GSM network does not include the growth of related $3 \mathrm{G}$ or $4 \mathrm{G}$ networks. The image is derived from Fig. 2 in Overeem et al. (2016).

tion (Dash and Ogutu, 2016) and this will only be realized through synergistic exploration and leadership from government space agencies, the science community, and increasingly the private sector. An underlying assumption here is that space junk will not continue to accumulate to the point of becoming an intolerable risk to launching satellites to low Earth and geosynchronous orbits: though that dystopia would actually enhance the importance of the sub-orbital alternative technologies described throughout this section. Whether intrinsic barriers (e.g. payload launch) or a divergence of commercial motivation versus scientific research interests will inhibit this exciting and much needed development in EO are topics that are explored further in Sect. 4.2.

\subsection{Mobile phones and citizen science}

While space-based and near-Earth sensing platforms are revealing entirely new avenues of EO, there are technologies closer to home that are also revolutionizing how we can monitor, sense, and interact with the environment around us. Smartphones have transformed entire societies, from the most developed countries to regions where a regular source of electricity or freshwater is still lacking. Data from 2013 estimated that there are 7.3 billion mobile subscriptions globally, with 3.2 billion of these linked to smartphones ${ }^{3}$ (see Fig. 5). Undoubtedly this number has increased in the last

\footnotetext{
${ }^{3}$ https://www.ericsson.com/mobility-report.
}

few years. Given their ubiquity, they present an ideal platforms from which to harness the possibilities of remote sensing hydrologic and related variables, as well as providing a means of information exchange. In Africa, one of the world's fastest growing regions for mobile phone subscribers (numbering more than 330 million as of mid-2016 ${ }^{4}$ ), mobile banking has allowed Kenya to lead the world in mobile money via its M-PESA system (Aker and Mbiti, 2010), while the delivery of information via text messaging has improved the economic outcomes of subsistence farmers through simple knowledge of market prices (Wyche and Steinfield, 2016). Other approaches have exploited mobile camera capabilities combined with smartphone applications to monitor soil, vegetation, and land use changes (Herrick et al., 2017). In this sense, a person with a smartphone can become a remote (or at least proximal) sensing platform capable of providing information on the environment around them. This concept of harnessing widely accessible technology and the users deploying it is broadly referred to as "citizen science", and has the potential to reshape how information is both collected and interpreted (Buytaert et al., 2014).

But simple image-capturing examples belie the potential that mobile devices have in providing a distributed measurement network. Plug-in and Bluetooth technologies linked to smartphones enable potentially billions of users to become

\footnotetext{
${ }^{4}$ http://interactive.aljazeera.com/aje/2016/ connecting-africa-mobile-internet-solar/connecting-africa.html
} 
"sensors" for measuring actual hydrological events. As an example of the immediate potential of this sensing platform, iBobber is a USD 100 baseball-sized fishing bob that measures water depths and temperatures and has GPS location capabilities (see http://reelsonar.com; noting that there are other similar devices available on the market). Fishermen everywhere could be recording water depths for river hydraulic models and for total storage in lakes. In a more focused manner, teams of lay scientists could be easily trained to use such low-cost devices to provide remotely sensed water depths in cost-effective ways, e.g. a leisurely riverboat excursion or simple fishing pole cast from the shoreline to yield water depths. It is not hard to envisage numerous other smartphoneenabled devices that auto-upload their measurements to the internet. Indeed, it is the ubiquity of smartphones that enables the imagining of new hydrologic measurements.

However, there are (at least) two challenges with such "citizen science": (1) making certain that the measurements are accurate; and (2) connecting the hydrologic researcher with the smartphone users. Both challenges are solvable using standard methods employed in hydrological sciences. For instance, data assimilation and other statistical approaches can ensure that measurements collected from disparate platforms are appropriately integrated in hydrologic models. In terms of engagement or outreach, cross-disciplinary interaction between the social and physical sciences could facilitate the implementation of strategies to effectively engage citizen science. One application where smartphones have already demonstrated their potential for environmental monitoring is their use as thermometers. Overeem et al. (2013b) showed that thousands of smartphone battery temperatures uploaded to a central database through an Android application could be employed to estimate daily mean air temperatures in eight major cities around the world with reasonable accuracy. Their results show the potential of "crowd sourcing" for real-time temperature monitoring in urban areas, where dedicated temperature measurements by meteorological services are typically lacking. Recent reviews have further illustrated the success of a number of crowd-sourcing projects, detailing the use of mobile video and imagery to capture and analyse flash flooding, debris flow, and flow velocities (Le Coz et al., 2016), precipitation events (Allamano et al., 2015) as well their application in atmospheric and climate sciences (Muller et al., 2015), detailing an exciting avenue of enhanced data collection.

Importantly, crowd sourcing in hydrology is not solely about smartphones. de Vos et al. (2017) report on an effort to source rainfall data from personal weather stations in Amsterdam, exploiting the proliferation of low-cost stations designed for home-based meteorological collection. Even in this single-city-focused example, more than 60 inhabitants were found to operate personal weather stations equipped with tipping bucket rain gauges within the Amsterdam metropolitan area, significantly increasing the sole rain gauge operated by the Royal Netherlands Meteorolog- ical Institute at Amsterdam's Schiphol Airport. While there are undoubtedly issues associated with poor siting considerations, (lack of) maintenance, and (interrupted) connectivity that would need to be accounted for, the utility of such additional hydrological monitoring is obvious. Indeed, the de Vos et al. (2017) study highlighted the additional information on the space-time variability of rainfall over a densely populated area that could be retrieved with reasonable accuracy and reliability from such a citizen network. A larger-scale example includes the Community Collaborative Rain, Hail, and Snow Network in the USA, (https://www.cocorahs.org/), which receive approximately 20000 daily rain-gauge reports from citizen scientists across North America (Reges et al., 2016). In a particularly novel application of exploiting existing networks of data, Rabiei et al. (2016) inferred rainfall by utilizing a vehicles GPS location together with sensors attached to the cars windscreen wipers. Many late-model vehicles employ infrared (or optical) sensors to determine rainfall intensity in order to automatically adjust the wiper rate, offering the possibility of providing distributed records of rainfall: albeit limited to the road network.

The use of non-traditional sources of information to infer, improve, or inform upon our hydrological understanding, as well as to expand the distribution and spatio-temporal representation of existing networks, is a rapidly growing field that presents clear potential. The topic is explored further in the section below, which details related examples of opportunistic sensing.

\subsection{Signals of opportunity}

The modern world is full of sensors, from the cars we drive, to the mobile phones (and cameras) we carry in our pockets. We are in the age of the "internet of things", where every day physical devices are connected to the network, sensing the world around us. Although related to the concept of "citizen science" that was introduced in Sect. 3.5, we couch the present discussion under the context of "opportunistic sensing": the concept of utilizing signals from often unrelated measurements to inform upon hydrological processes. Inferring hydrological properties by making use of signals of opportunity is a growing area of research.

Telecommunication engineers have known for a long time that radio signals propagating from the transmitting to receiving antennas of microwave links used in cellular communication networks are attenuated by rainfall. By using this knowledge, researchers have been able to translate this electromagnetic "noise" into a hydrometeorological "signal" (Messer et al., 2006; Leijnse et al., 2007). Indeed, it turns out that for the radio frequencies typically employed in such cellular networks, the signal attenuation is nearly linearly related to the average rainfall intensity. The attenuation can be inferred from the transmitted and received signal levels, which are operationally stored by telecommunication companies at regular time intervals (typically $15 \mathrm{~min}$ or less) to monitor 
network quality. As these links typically have lengths of a few kilometres and are installed at just a few tens of metres above the ground, they can be considered as path-averaged rain gauges, well suited for hydrological applications. Several thousand of such links across the Netherlands have recently been used to produce 15 min rainfall maps of comparable quality to those obtained from gauge-corrected groundbased weather radars (Overeem et al., 2013a, 2016). In addition to rainfall monitoring over urban areas ${ }^{5}$ (where network densities are generally high), this technique offers much potential for high-resolution measurement in areas where the density of ground-based monitoring networks (i.e. gauges or radars) is typically low, such as in developing countries (Doumounia et al., 2014; Gosset et al., 2016).

Given their spatial and temporal advantage, there is a long history of using radio occultation measurements via the GPS of satellites to infer atmospheric variables and profiles (Kursinski et al., 1997) for use in numerical weather prediction. More recent work has sought to expand the type of measurements that can be inferred between satellite links and ground stations. For example, Barthès and Mallet (2013) described the use of an Earth-space link in the Ku-band to measure rainfall, leveraging several hundred telecommunications satellites transmitting in this frequency to infer periods of rainfall via signal propagation through the troposphere. Such information is not only useful for hydrological applications but also for ground validation of satellite-based rainfall retrievals.

While improved representation of rainfall is of importance to hydrological studies, soil moisture plays an equally significant role in many process investigations. The use of proximal remote sensing techniques to measure soil water content and soil properties at depths deeper than current remote sensing capabilities (i.e. greater than $5 \mathrm{~cm}$ ) represents an area of considerable interest. One of the best example of opportunistic proximal sensing is the Plate Boundary Observatory $\mathrm{H}_{2} \mathrm{O}$ initiative, which uses reflected GPS signals to estimate soil moisture (Larson et al., 2008), snow depth (Larson et al., 2009), and vegetation growth (Small et al., 2010). Some of the advantages of this technique include the provision of temporally continuous data at scales $\left(\sim 1000 \mathrm{~m}^{2}\right)$ that fill a gap between point measurements and satellite remote sensing footprints, and that cloud cover and labour are not issues. Another approach that seeks to bridge the point-to-footprintscale divide is the COsmic-ray Soil Moisture-Observing System (COSMOS) (Zreda et al., 2012), which provides an increasingly rich dataset for calibration, validation, and evaluation of remote sensing products and land-surface models. Comprising a growing network of more than 200 cosmicray neutron probes at fixed installations across six continents, these data represent a valuable source of independent infor-

\footnotetext{
${ }^{5}$ See

http://www.nature.com/news/ mobile-phone-signals-bolster-street-level-rain-forecasts-1.21799.
}

mation from which a range of hydrological responses may be inferred or assessed (Jana et al., 2016; Montzka et al., 2017).

A recent addition to the COSMOS program has been the use of mobile "rovers", which offer a way to increase the spatial coverage from the local to mesoscales (Desilets et al., 2010; Chrisman and Zreda, 2013), while also offering a means to merge data from fixed probes to provide a multiscale real-time soil moisture product (Franz et al., 2015). In addition to supporting hyper-resolution land-surface modelling needs, the rover approach provides opportunities not only in research but also commercial activities; most notably in precision agriculture, e.g. mounting rovers to existing farm equipment (sprayers, tractors, etc.), autonomous farm vehicles, or to rotating infrastructure (i.e. centre-pivot irrigation systems), offers an interesting opportunistic sensing possibility. The capacity to mount probes on delivery trucks, self-driving vehicles, or even national train networks would further expand observational capacity and provide semi-repeatable local and regional mapping opportunities across both natural and urban landscapes. Mobile sensors can easily collect data from either ground vehicles (e.g. snow mobiles, dog sleds) or low-flying aircraft, which offers a potentially unprecedented calibration, validation, and evaluation dataset for a range of hydrological variables. While roving probes are fairly heavy $(50+\mathrm{kg})$ and miniaturization options are somewhat limited, the use of drone swarms with several smaller probes functioning as a single unit would further increase mapping possibilities (see Sect. 3.2). With the simultaneous use of several detector energies (bare, cadmium shielded, and plastic shielded probes) recent research has illustrated the means to collect information on vegetation condition, soil organic properties, and soil moisture simultaneously, providing a valuable resource to support observation and modelling strategies (Andreasen et al., 2016). Such sensing technology also has the potential to augment ongoing global digital soil mapping efforts (Sanchez et al., 2009), as well as aid in the validation of existing high-resolution products (Chaney et al., 2016).

In a final example of opportunistic sensing, we examine the potential of commercial passenger and cargo aircraft as mobile airborne sensing platforms. While observations from dedicated aircraft are typically only collected during sensor testing and infrequent, targeted measurement campaigns, there is little to inhibit (at least from a scientific perspective) airborne sensors from hitching rides aboard commercial aircraft, greatly expanding their spatial and temporal datacollection capabilities. Many airliners are already outfitted with Doppler radar and Aircraft Meteorological Data Relay (AMDAR) systems (Drüe et al., 2008), which provide measurements of meteorological variables that include temperature, wind vector, and dew point temperature, and are made available for assimilation into weather forecast models (Petersen, 2016) and for other scientific investigations deemed beneficial to the airlines (Sharman et al., 2014). Advanced sensors for measuring water vapour more precisely 
have also been tested alongside AMDAR sensors, while the benefits of including on-board infrared sensors (e.g. for volcanic ash detection) have recently been demonstrated (Prata et al., 2016). While leveraging the remote sensing potential of commercial aircraft is an approach that has been espoused for more than 2 decades (Fleming, 1996), it has yet to be routinely employed to enhance hydrometeorological observation. No doubt this is due in part to some of the obvious constraints on retrofitting aircraft with non-essential instrumentation, and the regulatory hurdles that would be faced in doing this. However, given that the systems described above all seek to enhance flight safety either directly (i.e. improved hazard detection) or indirectly (i.e. improved forecasting and early-warning systems), such an observing system may see more operational integration into the future.

\subsection{High-definition video from space}

One of the most exciting remote sensing opportunities that has the potential to change not only the way we observe the Earth system, but also the manner in which we can use data to inform on processes, is the emergence of highdefinition (HD) digital video. This game-changing visualization approach builds on a surprisingly long history of employing airborne video in EO studies (King, 1995). Indeed, some of the earliest satellite missions such as Landsat 1-3 (Townshend, 1981) used vidicons, a type of cathode-ray tube employed in capturing television images (Nagy and Nagy, 1972); although due to the temporal sampling limitations of the deployed systems, these were basically 2-D image snapshots, i.e. essentially television cameras providing still photographs (Vaughan and Johnson, 1994). While the use of airborne and ground-based optical and multispectral video systems have been explored actively in vegetation and agricultural studies (Everitt et al., 1991), it is only in very recent times that the capacity to exploit full-motion HD video from space has emerged. Indeed, it is this opportunity to utilize the temporal insights that HD video allows that represents the truly revolutionary aspect of this observing system.

With full-motion video imagery comes the capacity to capture dynamic hydrology and meteorology, providing new insights that could enhance our process understanding. An ability to record the Earth system in real-time on a repeatable basis has inter-disciplinary implications. Pollution monitoring, disaster management and response, ecosystem assessment, as well as numerous and immediate hydrological applications are imaginable, e.g. flow velocity, flood propagation, erosion monitoring, contaminant transport and dispersion, precipitation, and cloud tracking to name but a few. One novel application lies in the use of satellite video data to reconstruct a digital surface model (d'Angelo et al., 2016) via structure-from-motion-type approaches, providing details of landscape changes in ways that static elevation datasets cannot. Being able to record debris flow down a river, or dynamic inundation in natural or urban systems could provide new insights into how we model, forecast, and predict flow and related hydrological events. However, while the possibilities of video imagery from space are exciting, as a discipline we are under-prepared to utilize such data effectively. Ultra-high temporal resolution information is not something we routinely deal with, and therefore how to exploit such data will require innovation and imagination. An obvious constraint in current modelling application is that the temporal resolution of even the most advanced hydrological schemes are usually of the order of minutes rather than seconds (Berne et al., 2004; Ochoa-Rodriguez et al., 2015). Direct ingestion is the most obvious (but least imaginative) manner in which video data could be used, but computational and model-physical constraints are apparent. So, while a range of applications can be imagined, the practicalities of integrating or ingesting high-temporal sequences into our current modelling or analysis frameworks remain largely unexplored. Indeed, video imaging and analysis is more the domain of the computational scientist than the hydrologist, and therefore these disciplinary lines will need to be crossed to take advantage of such technological breakthroughs. Although the potential applications are many, a paradigm shift away from the use of periodic 2-D snapshots will be required to exploit the feature-rich temporal dimensions offered by video streams.

It is important to note that this is not blue-sky research: the technology exists, satellites are already in orbit, and data streams are available, but we are not keeping pace with the rapid advance in imagery possibilities. Indeed, it is the private sector that is leading the charge in realizing and utilizing the technology, with Google's TerraBella (recently acquired by Planet) providing high spatial (approx. $1 \mathrm{~m}$ ) and temporal (30 fps - frames per second) full-motion video imagery (Murthy et al., 2014). UrtheCast (https://www.urthecast.com/) is another company exploring this potential, with similar spatial $(1 \mathrm{~m})$ but lower temporal (3 fps) specifications (see Fig. 6): although the second generation UrtheCast system that is due for launch in late 2017 will provide imagery at $0.5 \mathrm{~m}$ and $30 \mathrm{fps}$, in addition to having a $1 \mathrm{~m}$ resolution X-band and $5 \mathrm{~m}$ resolution L-band SAR (Beckett, 2015). At the moment, both video platforms are limited to between 60 and $90 \mathrm{~s}$ captures, but expanding this technology to allow for full-coverage real-time observation in low Earth orbit has been proposed on micro- and nanotype satellite configurations (Han et al., 2015). Others have presented a vision of a geostationary space surveillance system (Airbus GO-3S) (Villien et al., 2014). Regardless of the platform, it is the combination of high-spatial and hightemporal observation that has the potential to dramatically alter the very nature of Earth observation.

\subsection{Cloud computing and data analytics}

In parallel to developments seen in other fields, novel EO satellites are acquiring data at a staggering rate, where even a single-satellite collection can exceed many terabytes on a 


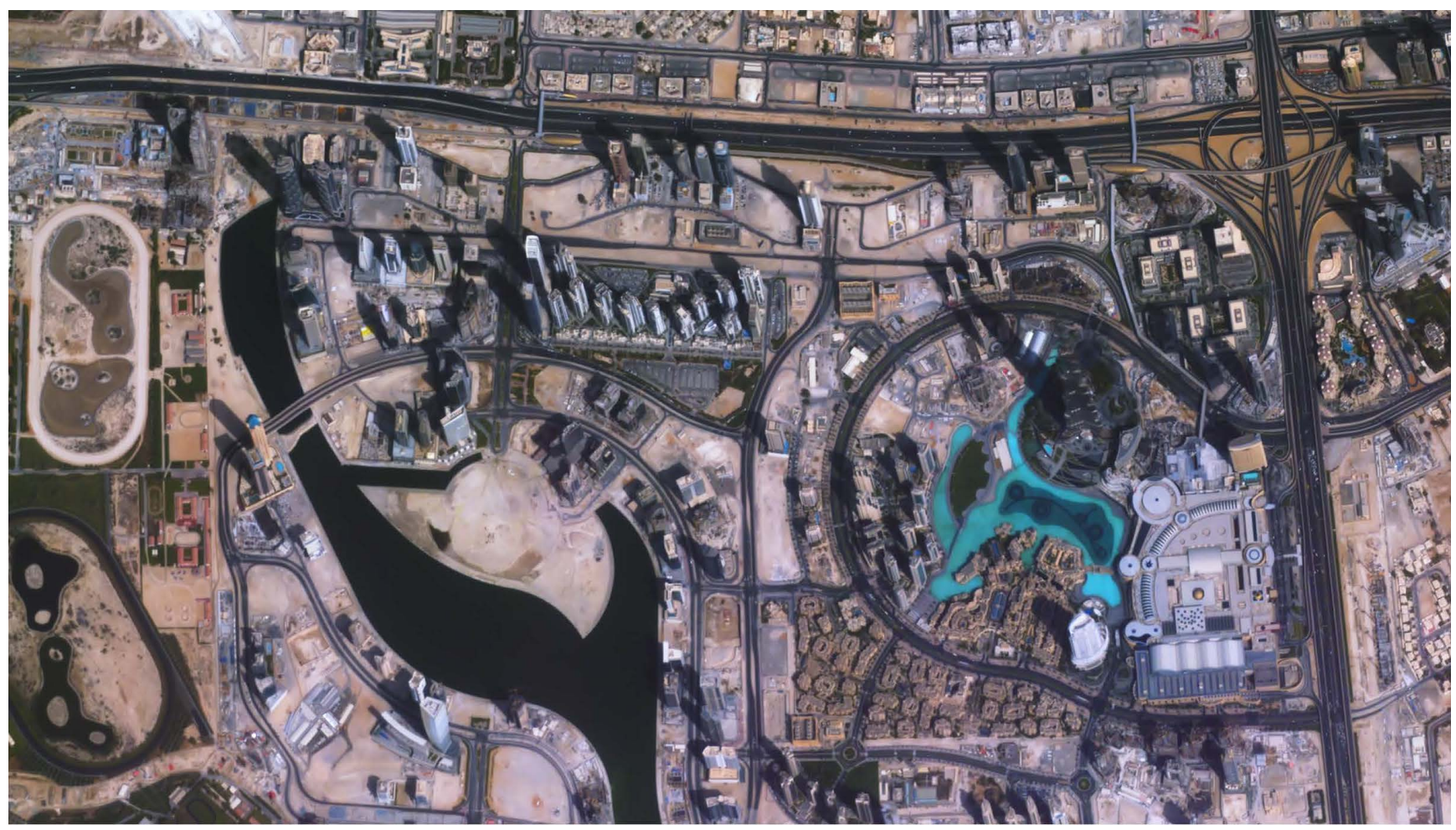

Figure 6. On-board the International Space Station, the Urthecast IRIS high-resolution camera (HRC) captures colour video at three frames per second for a duration of $60 \mathrm{~s}$. Here we see an example of the HD Video over the Burj Khalifi in Dubai. The tracking of vehicles on roads is analogous to monitoring flow in rivers or the speed of moving clouds, while the capacity to extract 3-D structure of the underlying terrain provides opportunities in dynamic monitoring of surfaces. The HD video can be viewed and downloaded at https://doi.org/10.5446/21698.

daily basis. Therefore, while the capacities of today's EO sensors to collect data of relevance to hydrology are truly unprecedented, the challenges faced when trying to turn the raw satellite data into useful information can be daunting. Over the regular lifetime of a satellite, more than a petabyte of raw satellite data can easily accumulate. It is by no means clear when or to what extent hydrology will fully exploit this rapidly increasing volume and diversity of EO data. However, the speed of adoption will likely be determined by the time it will take to move the vast quantities of EO data and their processing into the "cloud". This is because processing such large data volumes is impossible with standard computing resources, nor is it meaningful to distribute the data over the internet, thereby replicating many thousands of queries. Instead, the only way forward will be to "bring the users to the data". In practical terms, this means that EO data processing will increasingly take place in large virtualized data centres, allowing large numbers of users to access the data and enabling collaboration on the development and use of EO data. At a very basic level a cloud can be understood to be a large-scale computing infrastructure capable of delivering EO services over the internet. A key enabler of cloud computing was the construction and operation of extremely large-scale, commodity-computer data centres at low-cost locations to achieve economies of scale (Arm- brust et al., 2010). Currently, with falling prices for storage and computing, thematic aspects and service quality is becoming more and more important. Some of the advantages of cloud computing include virtualized resources, parallel processing, and data-service integration with scalable data storage (Hashem et al., 2015). With the existence of such infrastructure, it becomes possible to start building multi-level EO data-processing chains in a collaborative manner.

The adoption of cloud-computing technologies in EO and hydrology will not be without its challenges. Apart from the practical software-based considerations that allow for virtualization of large computing infrastructures with hundreds to thousands of users, a much larger obstacle is how best to organize the expert community, ensuring that joint efforts to develop code and products lead to quality-controlled, welldocumented, and user-friendly software and data. Ideally, interpretive models and subsequent data analysis would be run where the EO data reside, ensuring a seamless processing line from the raw sensor data to the final hydrologic predictions, allowing each expert along the value-adding chain to focus on his or her competencies. Considering the increasing complexity of scientific algorithms and models used in EO and hydrology, such collaboration can be expected to speed up research and development efforts, leading to a much faster data uptake in hydrological practice. Precisely where this 
cloud computing might take place also raises questions (and potential concerns) related to data archiving, distribution and intellectual property. One of the most advanced cloud platforms is Google's Earth Engine (http://earthengine.google. com), which provides a platform for petabyte-scale scientific analysis and visualization of geospatial datasets, both for public benefit (non-commercial use is for free) and for business and government users. Its data catalogue contains a wide variety of popular, curated datasets, including the world's largest online collection of Landsat scenes (Gorelick, 2013). Amazon Web Services offers a similar storage and analytics platform, which houses an expanding collection of satellite, meteorological, and climate datasets available to the user community, including recent Sentinel-2 data and number of NASA collections (http://aws.amazon.com/earth). Earth observation data archiving and stewardship are relatively new concepts to these more commercially oriented services, and therefore it is unclear how effectively they will embrace the scientific model of data retention: especially if the revenue potential of older data does not justify its storage. Whether government agencies will continue to maintain their own storage services or leverage these much larger commercial facilities also remains to be seen. Regardless of any future delivery mode, ensuring continued free-access and long-term archiving of stored Earth observations is essential to advancing the field. With the rise of artificial intelligence and deeplearning approaches (discussed below), the importance of maintaining a long record of "training data" may provide a commercial incentive to archive historical records.

A number of early examples have explored the hydrologyrelated opportunities afforded by cloud-based platforms (McGuire et al., 2014; Astsatryan et al., 2016). Donchyts et al. (2016) employed the Earth Engine for mapping surface water changes at $30 \mathrm{~m}$ over the past 30 years on a global scale, an effort that would not have been possible without such data analytic centralization. While the Earth Engine is popular amongst scientists, Amazon's cloud is increasingly being used by commercial companies to showcase their EO services, such as the Sentinel-2 web mapping service offered by Sinergise (http://www.sentinel-hub.com). Another cloud platform serving both EO and hydrological applications is currently being built by the Earth Observation Data Centre (EODC) for Water Resources Monitoring (https://www.eodc.eu/), a public-private partnership with a goal to foster the use of EO data for monitoring global water resources (Wagner et al., 2014). In addition to optical data (i.e. Landsat, Sentinel-2) EODC holds a complete global archive of Sentinel-1 SAR data, which can be processed with a supercomputer for continental to global-scale mapping of soil moisture, water bodies, and other hydrological parameters (Elefante et al., 2016). Clearly, there are many potential and diverse applications of cloud computing in hydrology, some of which are being enabled by access to the underlying applications program interface (API), a common feature of many of the Silicon Valley-type start-ups.
Although representing rather focused examples of cloudcomputing opportunities, the cases noted above serve to illustrate that this revolutionary change in technology, which has the potential to completely overhaul working practices in EO and hydrology, has already started. As the spatial and temporal resolution of EO data increases, the development of efficient cloud-computing, storage, and on-the-fly processing solutions becomes even more relevant. This is especially pertinent for a community that seeks to embrace the concept of hyper-resolution hydrological modelling, where the scales of processing and data requirements start to pushback on available computational power and resources (Bierkens et al., 2015). Undoubtedly, any future EO strategy in the hydrological sciences will have cloud computing as a core element, and therefore recognizing and resolving the inevitable challenges and opportunities that cloud computing will bring to the community will be key to realizing its potential.

A parallel consideration that will follow any increase in data volumes and the associated computing demands is the need to explore more efficient approaches to exploit and interpret the petabytes of satellite data being collected on a routine basis (Warren et al., 2015). The era of big data and artificial intelligence is upon us: whether we are prepared for it or not. Traditional modelling and analysis techniques are ill designed to interrogate or utilize immense EO datasets, and alternatives based on machine- and deep-learning methods that can be used for regression or classification problems involving massively multivariate systems are becoming increasingly popular. These data-analytic techniques have the potential to either completely replace process-based models, or work in combination to make them less computationally expensive (Lary et al., 2016). Commonly used machinelearning methods include artificial neural networks, support vector machines, genetic programming, decision tress, or random forests, amongst many other approaches. These approaches are usually applied in a "supervized" context, in which a database subset is used to train the algorithm to reproduce an expected response (i.e. "learning process"), and a different subset can be used to test or validate the performance of the trained algorithm. An interesting characteristic of these methods is that little to no knowledge of the physical processes underlying the observed variables is required to implement them, which releases their potential for discovering unexpected relationships as new hydrological and climatic observations become available (Faghmous and Kumar, 2014; Lary et al., 2016).

Machine-learning methods have been applied across a range of science and engineering applications for more than 2 decades. A number of recent examples have targeted the (retrospective) prediction or retrieval of hydrological states and fluxes from single- and multi-satellite sources, including the estimation of typhoon rainfall over the ocean (Chen et al., 2011), the retrieval of surface soil moisture (RodríguezFernández et al., 2016) and water vapour content (Aires et al., 2001), the estimation of river runoff (Rasouli et al., 2012; 
Deo and Şahin, 2016), the analysis of global hydro-climatic controls on vegetation (Papagiannopoulou et al., 2017), the training of high-resolution sensors for retrieval of NDVI (Houborg and McCabe, 2016), and the derivation of continental water and carbon fluxes using decision trees (Jung et al., 2009). Still, the application of these techniques to dynamically monitor hydrological events and processes using remote sensing remains an emerging field, with relatively limited existing applications. With the storage and analysis opportunities afforded by cloud computing, the capacity to streamline many of these examples into on-the-fly applications is more a reality than ever before, providing a new and on-demand observation and analysis source.

Despite this remarkable confluence of data science and remote sensing, one can still resist the narrative that there is no problem that a sufficiently complex machine-learning algorithm cannot unravel given enough data (Anderson, 2008). If this were the case, there would be no need for domain expertise to understand current and future challenges in hydrology: the dilettante will have prevailed (Klemeš, 1986). Indeed, there remain several obstacles to any predicted ascension of a completely data-driven approach to hydrology. Observations of the hydrosphere often have a spatio-temporal structure that emerges in the form of correlations between variables, but this correlation may not necessarily imply causality. Therefore, being able to draw strong deterministic conclusions about the behaviour of hydrologic systems based on data-driven methods often requires prior knowledge (and understanding) of the physical processes (Faghmous and Kumar, 2014). As an example, Papagiannopoulou et al. (2017) discussed how the application of random forest models to auto-correlated vegetation imagery and cross-correlated temperature and precipitation can lead to the wrong conclusion that temperature controls vegetation growth in waterlimited regions. Changing sensors or satellites (e.g. as part of data-continuity missions) routinely result in temporal gaps, discontinuities, and artefacts. In addition to inherent sensor degradations, these influences, without context, would impact any conclusions that data-driven models may yield on the behaviour of hydrological systems. All of this is to say that without subject knowledge, such temporal record adjustments are unlikely to be diagnosed or interpreted appropriately.

On the other hand, a dogmatic approach to a purely physically based hydrological process representation has inevitable limits to advancing understanding. The concept of "letting the data speak for itself" is particularly attractive in a discipline where so much of our physical understanding is based on a relatively simplistic description of process form and function, and where its application is routinely extended beyond the scales at which it was observed to be relevant. As both hydrological and remote sensing research progress, it is prudent that we (at least initially) seek the middle ground, where the development of machine-learning methods might be guided by theoretical constraints and understanding, and that they be used to complement or improve more traditional physically based models, which in turn can add interpretability with regard to the underlying processes. Regardless, the opportunities being presented by these new and innovative approaches are likely to challenge our concept of hydrology as a discipline, especially as the exploration of interdisciplinary datasets provide new insights and understanding to hydrological processes and behaviour: a topic that is expanded upon in the context of a fourth paradigm in hydrology, as discussed in Peters-Lidard et al. (2017).

\section{The changing Earth observation landscape}

We have examined some of the challenges and issues associated with satellite-based hydrological remote sensing (Sect. 2) and reviewed the innovative and exciting frontiers of emerging Earth observation technologies (Sect. 3). To conclude this synthesis, we present a brief overview on some of the important considerations that may influence how this vision for the future of EO will be realized, highlighting the roles that government space agencies and commercial enterprises may play in reshaping the field, and identifying some of the potential drawbacks, constraints, and limitations that may emerge as we navigate this rapidly evolving landscape.

\subsection{The space agency approach}

Space agencies are government entities that are tasked with undertaking and enabling the development of space-based science and technology. In the USA, approximately $25 \%$ of NASA's USD 19 billion budget goes to funding the science program, of which USD 2.0 billion is allocated to Earth Science ${ }^{6}$. With these resources, NASA supports 60 operating satellite missions, 35 which are in the planning stages, and over 10000 US scientists, as well as funding more than 3000 research grants (NB these include awards to planetary science, astrophysics, and Earth science). Other space agencies are smaller, but still have USD 2-5 billion budgets, e.g. ESA, ROSCOSMOS, CNES, DLR, and JAXA. While the budget numbers seem quite large, space agencies are still challenged to afford the suite of desired satellite missions that satisfy a diverse scientific community as well as government needs. The cost of design, launch, and operation of a satellite mission has increased considerably over the last few decades. Satellite missions 20 years ago cost of the order of USD 100 million, but today, they can reach up to (and beyond) USD 1 billion. Agency budgets, however, have not grown by a similar magnitude. Indeed, measured in 2014 dollars, NASA's budget has remained around USD 20 billion for over 3 decades.

To forecast the types of future missions that will be launched by space agencies, we can look to their plan-

\footnotetext{
${ }^{6}$ https://www.nasa.gov/sites/default/files/atoms/files/fy_2017_ nasa_agency_fact_sheet.pdf.
} 
ning process to evaluate the historical success at following such plans. The best known amongst the space agency planning efforts for Earth observation is the National Academies Earth Science and Applications from Space "Decadal Survey" (2007): an Herculean effort that energized the Earth science community to gather and prioritize NASA's future EO capacity. The endeavour identified 15 new missions for consideration as well as urging NASA to launch two additional missions already in mature planning stages, i.e. GPM and a replacement for Landsat 7. The GPM core observatory launched in February 2014, following Landsat 8 in February 2013. However, of the original 15 new missions proposed in the Decadal Survey, SMAP (Entekhabi et al., 2010) is the only one to have launched (in January 2015). Other missions were already in various stages of planning before the Decadal Survey, including the SWOT mission (Biancamaria et al., 2011), which was initiated 5 years prior to 2007. All of this is to illustrate that it is not unusual for government space agency missions to take of the order of 2 decades to go from concept to launch (see Sect. 3.1), and that the systems that move from proposal to orbit are not always identified by consensus. Indeed, sometimes an entire generation of scientists move through the community before the space-based measurement system arrives in orbit.

An important consideration, particularly in the light of the "fast and nimble" approach advocated by Silicon Valleydriven commercial enterprises, is that by the time any government satellite actually reaches orbit, the technology onboard may already be a decade (or more) old. The obvious implication of this is that space agencies may not be launching the most cutting edge sensing platforms. Indeed, by their nature, space agencies are risk averse, seeking out the most robust technology to survive the hazards of space and ensure delivery of mission objectives. This model stands in contrast to the technological advances being made today, especially in instrument design and function, which occur at a seemingly faster pace than in decades past. The emerging concept of "agile aerospace" combined with the opportunities being presented by commercial ventures via the rise of the CubeSat (see Sect. 3.4) and other sensing platforms present an ideal test bed for new technology and demonstrator systems; a theme that is explored in the following section.

\subsection{The commercialization of space}

The commercial sector presents something of a counter example to the government space agency approach. Undoubtedly, commercial enterprises build upon the successes (and sometimes direct funding) of the government sector. However, recent advances have seen an increased capacity to combine that foundation with venture capital and new technology to provide immediate EO platforms to the paying customer. Of the recent players operating in this market, perhaps the most well-known is Space Exploration Technologies (SpaceX) (http://www.spacex.com). Employing tech- niques such as 3-D printing to create strong and durable rocket parts at a fraction of the time taken for traditional casting, they have also re-imagined and re-engineered the reusable launch vehicle concept, representing a major innovation and cost saving to the delivery of payloads into space. An objective of these new rocket companies is to radically improve the efficiencies of payload delivery at a fraction of current costs, which have been estimate at up to USD 20000 per kg (Coopersmith, 2011). Indeed, the SpaceX approach purports to reduce costs by about half compared to traditional launch vehicles (e.g. USD 62 million for a $22000 \mathrm{~kg}$ payload on a Falcon 9 rocket) ${ }^{7}$. With a launch planned for late 2017, the SpaceX Falcon Heavy aims to reduce this cost further, lifting up to $54000 \mathrm{~kg}$ to low Earth orbit for USD 90 million, or USD 1700/kg (NB finding precise figures for this is difficult, as they are "reusable rockets" and the costs decrease as function of the number of planned launches). While not a reusable launch system, Rocket Lab (http://www.rocketlabusa.com), a New Zealand start-up, is offering smaller launch vehicle capability, but with greater frequency and selective orbit. Aimed specifically at the small satellite market, it will launch a $150 \mathrm{~kg}$ payload for USD 5 million and also provide a ride-sharing option where users can launch 1 to $12 \mathrm{U}$ CubeSats, opening up the prospect of investigator-led space missions.

But getting to space is only one aspect of the recent rise in commercial activity. As discussed in Sect. 3.4, there are a number of companies exploiting technological advances in sensor miniaturization, reduced power consumption and improved battery life (that have been driven in large part by the mobile phone industry) to produce cheaper, smaller and more efficient satellite platforms. One of the most ambitious of these ventures may be Planet (http://www.planet.com), a USD 200 million 7-year-old start-up with a stated goal of providing complete global coverage of the terrestrial surfaces of the Earth every day via a constellation of their CubeSat "Doves", representing an unprecedented high-resolution information resource (Houborg and McCabe, 2016). But Planet is just one of a number of non-agency-based companies playing a role in EO; DigitalGlobe, BlackSky, Planetary Resources, and Spire are just a few examples of private ventures that are operating largely independent of government space agencies.

Apart from the motivation and rationale of these companies shifting towards profit-making enterprises rather than operating for the social good, a key difference between government and commercial sector approaches to space is funding for scientific use. By very approximate calculation, NASA provides about one-tenth of a satellite missions cost for scientific users. Thus, a USD 1 billion mission might provide of the order of USD 100 million for related scientific activities. A private company, with a total budget of the order of a few hundred million dollars, would obviously place a much

\footnotetext{
${ }^{7}$ See http://www.spacex.com/about/capabilities.
} 
lower (or no) priority on directly funding the science community. However, while space agencies are certainly well motivated by science, the significant imbalance between technology and science funding indicates a strong vested interest in their supported technology engineering communities. In contrast, commercial enterprises are strongly motivated by profit; i.e. venture capitalists expect a return on their investment, and therefore optimizing efficiencies in production, launch and operation are paramount.

There are numerous examples of private-public partnerships that have shown the success of industry engagement, and many opportunities exist to exploit intersections of interest not only within industry but also with other government departments. Of course, putting satellites into orbit is only one small part of a space agency's mission. But what is becoming clear is that there are cheaper, faster, and more functional options being presented to the community from a variety of sources, both private and commercial, which present an opportunity to embrace a new era of EO beyond the traditional agency approach. In some ways, government space agencies are already adapting to leverage these changes in their own operations by sub-contracting out certain mission elements to the commercial sector, e.g. resupply of the ISS using SpaceX Falcon 9 rockets, along with the many satellite components built by private companies under government contract. Still, it remains unclear how individual investigators can best leverage these new observational platforms and the data they produce within the current mode of open-access, peer-review, and publication of results. Will hydrologists be able to afford this data, and once provided, will there be limitations on its use? There is a real risk that the successful commercialization of space could pose a serious threat to the function and operation of both space agency and investigator-led Earth observation, as well as scientific advancement that relies on freely available and abundant data (Tollefson, 2017). How the science community and the respective national space agencies respond to these opportunities (and risks) will go some way to defining the direction of hydrologic (and related) sciences over the next decade and beyond. Given our stakeholder position and vested interest in this, it would make sense to help shape the direction of these seemingly inevitable developments.

\subsection{Continuity and stability or disruption and opportunity}

As has become apparent, there are exciting future opportunities for hydrologic science that do not rely solely upon traditional space-borne approaches. The advent of low-cost UAVs, smartphones, and the global internet empower the individual researcher to collect their own measurements and drive and direct their own scientific goals. For instance, scientists and engineers are no longer reliant on space agency airborne campaigns that can take years to organize, cannot respond to fast-paced dynamic events (such as floods, droughts, extreme events), and are subject to the meteorological vagaries of the planned-in-advance experimental window (e.g. soil moisture campaigns that do not rain). But investigator-led approaches are often process-based and local in scale, and therefore determining whether or how they can they be scaled up to regional programs is an important objective. Likewise, and perhaps more importantly, ensuring that these distributed and often uncoordinated efforts can be more closely tied to existing space-based measurements or local-to-global monitoring programs is an issue requiring community attention.

Hydrologists, like all scientists, need measurements, models, and money to make discoveries. From our review, it seems inevitable that at least for the immediate (and somewhat) foreseeable future, there will be positive and negative outcomes for the EO community, with both technological changes and new players entering the space-based observation sphere. Although government agencies are unlikely to radically alter their EO programs (a positive), barring some unforeseen political event or paradigm shift, the moneys that space agencies receive have remained historically flat, while costs continue to rise (a negative). Therefore, while the positive enables a significant-sized research community, the negative is that there will likely be fewer satellites and hence a lower variety of needed measurements available to advance our understanding of the Earth system. Space agencies will surely do their best to continue funding for individual research communities, e.g. working groups and airborne campaigns for each unique sector studying their particular component of the water cycle, and such approaches may well lead to scientific discoveries. But these will inevitably be at local scales and not at the global scale that satellites are designed to address. Moreover, while the traditional space agency approach of a careful and often prolonged mission planning and approval schedule may lead to the eventual launch of a satellite measuring one aspect of the water cycle, there is no guarantee that other components will be simultaneously retrieved, and hence the error envelope of models (and observations) will remain unconstrained. One of the outstanding challenges of hydrological remote sensing remains to monitor (and close) the water cycle (McCabe et al., 2008; Sheffield et al., 2009; Y. Zhang et al., 2016a), yet an integrated water cycle observation strategy remains very much in the conceptual phase, with no planned mission on the horizon.

Over the last few years, the commercial sector has demonstrated that space is now "open for business". A singularly positive outcome of this is that there now exists a range of global VNIR near-daily to daily measurement platforms that are available (albeit at a cost) from the commercial sector, providing ultra-high resolution detail. These commercial sensors can provide data at a higher spatial and temporal resolution than comparable space agency systems (Dash and Ogutu, 2016), although the radiometric quality of the imagery may not always be as refined (Houborg and McCabe, 
2016). As already noted, there is generally no underlying scientific purpose or social good directly driving these efforts; commercial launches are ultimately driven by an economic incentive. Therefore, one negative resulting from this misalignment of purpose is that sensors that do not have an obvious income generating market are unlikely to be launched. For instance, active sensors have yet to make commercial inroads in the same way as optical sensors, and thus water cycle measurements that rely upon lidar or emitted radar pulses are not presently available (NB UrtheCast plans to equip their next-generation satellite with an X- and L-band active radar; see Beckett, 2015). But profit incentive is not the only difference separating these competing interests. Space agencies and the communities they serve often have an interest in data continuity; indeed, the Landsat mission has a legislated foundation to provide data "sufficiently consistent (in terms of acquisition geometry, coverage characteristics, and spectral characteristics) with previous Landsat data to allow comparisons for global and regional change detection and characterization" as part of the 1992 Land Remote Sensing Policy Act (US Code Title 15, Chapter 82) (Irons et al., 2012). In the light of technological advances (e.g. constellations of CubeSats) and other space agency sensors such as Sentinel-2, it could be argued that continuity of a particular mission or sensor type is no longer necessary, so long as the observations lack discontinuities caused by large spatio-temporal gaps or calibration issues. The point here is that unlike the scientific community, the commercial sector has no demand or underlying rationale for ensuring continuity beyond satisfying the needs of their particular business model. Likewise, if there is an economic incentive to pursue it, they can move quickly from one technology to the next without concern for the integrity of the long-term data record: a position that may not be as easily adopted by space agencies. Of course, a potential drawback of commercialization lies in the quality and assessment of the delivered products. While many space agencies now allocate a proportion of the mission budget for cal-/valrelated activities, this is not an aspect that would necessarily be considered by commercial ventures. The consequence of less stringent quality controls is that any data from new commercial platforms may contain poorly defined accuracies and sensitivities, hampering the process of time series and multisatellite data merging.

Given the somewhat meandering nature of research to applications, the commercial model may not seem to have immediate relevance to advancing scientific inquiry. However, there is much to be gained in leveraging and engaging with the influx of activity in the current race to space, particularly given the range and variability of measurements that can provide new insights into process scale and response and with a density and fidelity that has never been seen before. One aspect that is not clear is whether the commercial sector will ultimately be in competition, or in cooperation, with government funded space agencies. Noting that both groups provide VNIR-band imagery, it might seem that they are marketing the same product. Indeed, from an economics perspective, competition usually lowers costs. But given that space agency data are largely "free" to the scientific community (NB this ignores the very real cost of tax-payer funded mission launches and data collection, processing, and archiving), there would not seem to be any competitive advantage or level playing field. Clearly, the value proposition will be in resolution, timeliness, or in value adding, i.e. increasing imagery information content through derived or customerspecific products. How government space agencies might adapt to account for this commercial rise is unclear. There are threats, but also opportunities, particularly in the demonstration of new technologies and rapid delivery of payloads to space. There are also obvious risks in a solely commercially driven framework; uncertainties in financing, profit-making incentive, imagery costs, free-use policies, and freedom to publish are all potential inhibitors to unhindered scientific inquiry. The future is certainly not clear, but these are issues that require immediate consideration given what seems to be an inevitable advance towards a greater commercialization of Earth observation.

\section{Concluding remarks}

We have entered a new era of Earth observation, where the threshold for what can be sensed from small satellite, airborne platforms and even on-ground monitoring is rapidly changing and evolving. The EO technologies discussed throughout this synthesis show great potential to revolutionize and reinvigorate our understanding of hydrology and present a range of exciting platforms from which to develop new insights into hydrological process form and function. Our community has an opportunity to reshape hydrologic science across the spectrum from fundamental research to applications-based objectives. Either in isolation or (ideally) in combination, researcher-led, commercial and government-driven EO enterprises present new and innovative ways to envision both our own, and related disciplines. The alignment of circumstance and technology driving these advances have not happened in isolation, but reflect a convergence of innovation, breakthroughs in computational infrastructure and data storage, and opportunities for leveraging public and private assets collectively. Many of the EO advances discussed herein have arisen in just the past 5 years. What might the next 5-10 years have in stall? One possible scenario is contingent on the provision of global and lowcost internet access (see discussion in Sect. 3.3 and efforts such as http://oneweb.world/). Given some notable failures of previous attempts, the following remains rather speculative, but presents a plausible vision of the future. With an ever-increasing availability of low-cost sensors, the connectivity provided by a global internet would facilitate truly autonomous remote monitoring of the Earth system. Whether permanent, disposable, or even biodegradable, thousands of 
cheap devices could be deployed to measure soil moisture, precipitation, snow, stage, or any other imaginable variable (see van de Giesen et al., 2014), recording and broadcasting directly to the internet or through scheduled collection via targeted UAVs or sentry systems (balloons, solar planes) in more remote regions. In such a connected world, integrating these diverse EO sources, from space based to in situ, in order to optimize observing potential will be a key challenge. Technology is not the barrier to realizing such a future, as much of what is needed exists already. But embracing these technologies will require a radical rethink, not just on how data are collected, but how it is used and managed in our modelling and interpretation efforts, where the focus on pointprecision accuracy and error quantification can act as barriers to broader system understanding. While there are certainly challenges in realizing the potential of these emerging applications, there are game-changing opportunities as well, from the novelty of new sensing platforms such as CubeSats and UAVs, to the reshaping of the computational landscape through cloud-computing and data-analytic approaches. It is our hope that this forward-looking synthesis article will help to accelerate the adoption of these (r)evolutionary techniques and technologies. What is increasingly evident is that humans have the capacity to traverse all corners of the globe and have the technology required to measure or infer most variables of interest. It is possible that we may be the remote sensing platforms of the future.

Data availability. The high-definition video shown in Fig. 6, obtained from the UrtheCast IRIS sensor on board the International Space Station, can be viewed and downloaded at https://doi.org/10.5446/21698.

\section{The Supplement related to this article is available online at https://doi.org/10.5194/hess-21-3879-2017- supplement.}

Competing interests. The authors declare that they have no conflict of interest.

Special issue statement. This article is part of the special issue $O b$ servations and modelling of land-surface water and energy exchanges across scales: special issue in Honour of Eric F. Wood. It is not associated with a conference.

Acknowledgements. Matthew McCabe and Rasmus Houborg are supported by funding from the King Abdullah University of Science and Technology. We thank David Bonney for providing a sample of UrtheCast's IRIS high-definition video imagery (see Fig. 6). The authors also appreciate the thoughtful comments provided by Guido Salvucci, Chris Kummerow, Joshua Fisher and an anonymous reviewer.
Edited by: Dennis Lettenmaier

Reviewed by: Guid D. Salvucci and one anonymous referee

\section{References}

Aires, F., Prigent, C., Rossow, W. B., and Rothstein, M.: A new neural network approach including first guess for retrieval of atmospheric water vapor, cloud liquid water path, surface temperature, and emissivities over land from satellite microwave observations, J. Geophys. Res.-Atmos., 106, 14887-14907, 2001.

Aker, J. C. and Mbiti, I. M.: Mobile phones and economic development in Africa, J. Econ. Perspect., 24, 207-232, https://doi.org/10.1257/jep.24.3.207, 2010.

Alemohammad, S. H., Fang, B., Konings, A. G., Green, J. K., Kolassa, J., Prigent, C., Aires, F., Miralles, D., and Gentine, P.: Water, Energy, and Carbon with Artificial Neural Networks (WECANN): A statistically-based estimate of global surface turbulent fluxes using solar-induced fluorescence, Biogeosciences Discuss., https://doi.org/10.5194/bg-2016-495, in review, 2016.

Allamano, P., Croci, A., and Laio, F.: Toward the camera rain gauge, Water Resour. Res., 51, 1744-1757, https://doi.org/10.1002/2014WR016298, 2015.

Alsdorf, D. E., Rodríguez, E., and Lettenmaier, D. P.: Measuring surface water from space, Reviews of Geophysics, 45, RG2002, https://doi.org/10.1029/2006RG000197, 2007.

Anderson, C.: The end of theory: The data deluge makes the scientific method obsolete, in: Wired Magazine, https://www.wired. com/2008/06/pb-theory/ (last access: 26 July 2017), 2008.

Anderson, K. and Gaston, K. J.: Lightweight unmanned aerial vehicles will revolutionize spatial ecology, Front. Ecol. Environ., 11, 138-146, https://doi.org/10.1890/120150, 2013.

Anderson, M. C., Norman, J. M., Mecikalski, J. R., Torn, R. D., Kustas, W. P., and Basara, J. B.: A Multiscale Remote Sensing Model for Disaggregating Regional Fluxes to Micrometeorological Scales, J. Hydrometeorol., 5, 343-363, 2004.

Anderson, M. C., Hain, C., Otkin, J., Zhan, X., Mo, K., Svoboda, M., Wardlow, B., and Pimstein, A.: An Intercomparison of Drought Indicators Based on Thermal Remote Sensing and NLDAS-2 Simulations with U.S. Drought Monitor Classifications, J. Hydrometeorol., 14, 1035-1056, https://doi.org/10.1175/jhm-d-12-0140.1, 2013.

Andreasen, M., Jensen, K. H., Desilets, D., Zreda, M., Bogena, H., and Looms, M. C.: Can canopy interception and biomass be inferred from cosmic-ray neutron intensity? Results from neutron transport modeling, Hydrol. Earth Syst. Sci. Discuss., https://doi.org/10.5194/hess-2016-226, in review, 2016.

Armbrust, M., Fox, A., Griffith, R., Joseph, A. D., Katz, R., Konwinski, A., Lee, G., Patterson, D., Rabkin, A., Stoica, I., and Zaharia, M.: A view of cloud computing, Commun. ACM, 53, 50-58, https://doi.org/10.1145/1721654.1721672, 2010.

Astsatryan, H., Narsisian, W., and Asmaryan, S.: SWAT hydrological model as a DaaS cloud service, Earth Sci. Inform., 9, 401407, https://doi.org/10.1007/s12145-016-0254-6, 2016.

Aumann, H. H., Chahine, M. T., Gautier, C., Goldberg, M. D., Kalnay, E., McMillin, L. M., Revercomb, H., Rosenkranz, P. W., Smith, W. L., Staelin, D. H., Strow, L. L., and Susskind, J.: AIRS/AMSU/HSB on the aqua mission: Design, science objec- 
tives, data products, and processing systems, IEEE T. Geosci. Remote, 41, 253-263, https://doi.org/10.1109/TGRS.2002.808356, 2003.

Barnhart, D. J., Vladimirova, T., Baker, A. M., and Sweeting, M. N.: A low-cost femtosatellite to enable distributed space missions, Acta Astronaut., 64, 1123-1143, https://doi.org/10.1016/j.actaastro.2009.01.025, 2009.

Barthès, L., and Mallet, C.: Rainfall measurement from the opportunistic use of an Earth-space link in the Ku band, Atmos. Meas. Tech., 6, 2181-2193, https://doi.org/10.5194/amt-6-2181-2013, 2013.

Bastiaanssen, W. G. M., Menenti, M., Feddes, R. A., and Holtslag, A.: A remote sensing surface energy balance algorithm for land (SEBAL). I. Formulation, J. Hydrol., 212-213, 198-212, 1998.

Baur, O., Kuhn, M., and Featherstone, W. E.: GRACEderived ice-mass variations over Greenland by accounting for leakage effects, J. Geophys. Res.-Solid Ea., 114, B06407, https://doi.org/10.1029/2008JB006239, 2009.

Bayard, D., Stähli, M., Parriaux, A., and Flühler, H.: The influence of seasonally frozen soil on the snowmelt runoff at two Alpine sites in southern Switzerland, J. Hydrol., 309, 66-84, https://doi.org/10.1016/j.jhydrol.2004.11.012, 2005.

Beck, H. E., van Dijk, A. I. J. M., Levizzani, V., Schellekens, J., Miralles, D. G., Martens, B., and de Roo, A.: MSWEP: 3hourly $0.25^{\circ}$ global gridded precipitation (1979-2015) by merging gauge, satellite, and reanalysis data, Hydrol. Earth Syst. Sci., 21, 589-615, https://doi.org/10.5194/hess-21-589-2017, 2017.

Beckett, K.: UrtheCast second-generation earth observation sensors, International Archives of the Photogrammetry, Remote Sensing and Spatial Information Sciences - ISPRS Archives, 1069-1073, 2015.

Bellvert, J., Zarco-Tejada, P. J., Marsal, J., Girona, J., GonzálezDugo, V., and Fereres, E.: Vineyard irrigation scheduling based on airborne thermal imagery and water potential thresholds, Aust. J. Grape Wine Res., 22, 307-315, https://doi.org/10.1111/ajgw.12173, 2016.

Berne, A., Delrieu, G., Creutin, J.-D., and Obled, C.: Temporal and spatial resolution of rainfall measurements required for urban hydrology, J. Hydrol., 299, 166-179, https://doi.org/10.1016/j.jhydrol.2004.08.002, 2004.

Biancamaria, S., Durand, M., Andreadis, K. M., Bates, P. D., Boone, A., Mognard, N. M., Rodríguez, E., Alsdorf, D. E., Lettenmaier, D. P., and Clark, E. A.: Assimilation of virtual wide swath altimetry to improve Arctic river modeling, Remote Sens. Environ., 115, 373-381, https://doi.org/10.1016/j.rse.2010.09.008, 2011.

Bierkens, M. F. P., Bell, V. A., Burek, P., Chaney, N., Condon, L. E., David, C. H., de Roo, A., Döll, P., Drost, N., Famiglietti, J. S., Flörke, M., Gochis, D. J., Houser, P., Hut, R., Keune, J., Kollet, S., Maxwell, R. M., Reager, J. T., Samaniego, L., Sudicky, E., Sutanudjaja, E. H., van de Giesen, N., Winsemius, H., and Wood, E. F.: Hyper-resolution global hydrological modelling: what is next?, Hydrol. Process., 29, 310-320, https://doi.org/10.1002/hyp.10391, 2015.

Bormann, K. J., Westra, S., Evans, J. P., and McCabe, M. F.: Spatial and temporal variability in seasonal snow density, J. Hydrol., 484, 63-73, 2013.

Bouwmeester, J. and Guo, J.: Survey of worldwide pico- and nanosatellite missions, distributions and sub- system technology, Acta Astronaut., 67, 854-862, https://doi.org/10.1016/j.actaastro.2010.06.004, 2010.

Brando, V. E. and Dekker, A. G.: Satellite hyperspectral remote sensing for estimating estuarine and coastal water quality, IEEE T. Geosci. Remote, 41, 1378-1387, https://doi.org/10.1109/TGRS.2003.812907, 2003.

Brocca, L., Ciabatta, L., Massari, C., Moramarco, T., Hahn, S., Hasenauer, S., Kidd, R., Dorigo, W., Wagner, W., and Levizzani, V.: Soil as a natural rain gauge: Estimating global rainfall from satellite soil moisture data, J. Geophys. Res.-Atmos., 119, 51285141, https://doi.org/10.1002/2014JD021489, 2014.

Brooks, B. A., Glennie, C., Hudnut, K. W., Ericksen, T., and Hauser, D.: Mobile laser scanning applied to the earth sciences, Eos, 94, 313-315, 2013.

Buytaert, W., Zulkafli, Z., Grainger, S., Acosta, L., Alemie, T. C., Bastiaensen, J., De Bièvre, B., Bhusal, J., Clark, J., Dewulf, A., Foggin, M., Hannah, D. M., Hergarten, C., Isaeva, A., Karpouzoglou, T., Pandeya, B., Paudel, D., Sharma, K., Steenhuis, T., Tilahun, S., Van Hecken, G., and Zhumanova, M.: Citizen science in hydrology and water resources: opportunities for knowledge generation, ecosystem service management, and sustainable development, Front. Earth Sci., 2, 26, https://doi.org/10.3389/feart.2014.00026, 2014.

Calmant, S. and Seyler, F.: Continental surface waters from satellite altimetry, Comptes Rendus Geoscience, 338, 1113-1122, https://doi.org/10.1016/j.crte.2006.05.012, 2006.

Cammalleri, C., Anderson, M. C., Gao, F., Hain, C. R., and Kustas, W. P.: Mapping daily evapotranspiration at field scales over rainfed and irrigated agricultural areas using remote sensing data fusion, Agr. Forest Meteorol., 186, 1-11, https://doi.org/10.1016/j.agrformet.2013.11.001, 2014.

Carroll, M. L., Townshend, J. R., DiMiceli, C. M., Noojipady, P., and Sohlberg, R. A.: A new global raster water mask at $250 \mathrm{~m}$ resolution, Int. J. Digit. Earth, 2, 291-308, https://doi.org/10.1080/17538940902951401, 2009.

Chaney, N. W., Wood, E. F., McBratney, A. B., Hempel, J. W., Nauman, T. W., Brungard, C. W., and Odgers, N. P.: POLARIS: A 30-meter probabilistic soil series map of the contiguous United States, Geoderma, 274, 54-67, https://doi.org/10.1016/j.geoderma.2016.03.025, 2016.

Chen, L., Yeh, K. C., Wei, H. P., and Liu, G. R.: An improved genetic programming to SSM/I estimation typhoon precipitation over ocean, Hydrol. Process., 25, 2573-2583, https://doi.org/10.1002/hyp.8132, 2011.

Chen, X., and Vierling, L.: Spectral mixture analyses of hyperspectral data acquired using a tethered balloon, Remote Sens. Environ., 103, 338-350, https://doi.org/10.1016/j.rse.2005.05.023, 2006.

Chrisman, B. and Zreda, M.: Quantifying mesoscale soil moisture with the cosmic-ray rover, Hydrol. Earth Syst. Sci., 17, 50975108, https://doi.org/10.5194/hess-17-5097-2013, 2013.

Coccia, G., Siemann, A. L., Pan, M., and Wood, E. F.: Creating consistent datasets by combining remotely-sensed data and land surface model estimates through Bayesian uncertainty post-processing: The case of Land Surface Temperature from HIRS, Remote Sens. Environ., 170, 290-305, https://doi.org/10.1016/j.rse.2015.09.010, 2015. 
Coopersmith, J.: The cost of reaching orbit: Groundbased launch systems, Space Policy, 27, 77-80, https://doi.org/10.1016/j.spacepol.2011.03.001, 2011.

d'Angelo, P., Máttyus, G., and Reinartz, P.: Skybox image and video product evaluation, Int. J. Image Data Fusion, 7, 3-18, https://doi.org/10.1080/19479832.2015.1109565, 2016.

Das, N. N. and Mohanty, B. P.: Root zone soil moisture assessment using remote sensing and vadose zone modeling, Vadose Zone J., 5, 296-307, https://doi.org/10.2136/vzj2005.0033, 2006.

Dash, J. and Ogutu, B. O.: Recent advances in spaceborne optical remote sensing systems for monitoring global terrestrial ecosystems, Prog. Phys. Geogr., 40, 322-351, https://doi.org/10.1177/0309133316639403, 2016.

Denis, G., de Boissezon, H., Hosford, S., Pasco, X., Montfort, B., and Ranera, F.: The evolution of Earth Observation satellites in Europe and its impact on the performance of emergency response services, Acta Astronaut., 127, 619-633, https://doi.org/10.1016/j.actaastro.2016.06.012, 2016.

Deo, R. C. and Şahin, M.: An extreme learning machine model for the simulation of monthly mean streamflow water level in eastern Queensland, Environ. Monit. Assess., 188, 1-24, https://doi.org/10.1007/s10661-016-5094-9, 2016.

Desilets, D., Zreda, M., and Ferré, T. P. A.: Nature's neutron probe: Land surface hydrology at an elusive scale with cosmic rays, Water Resour. Res., 46, W11505, https://doi.org/10.1029/2009WR008726, 2010.

de Vos, L., Leijnse, H., Overeem, A., and Uijlenhoet, R.: The potential of urban rainfall monitoring with crowdsourced automatic weather stations in Amsterdam, Hydrol. Earth Syst. Sci., 21, 765-777, https://doi.org/10.5194/hess-21-765-2017, 2017.

De Wulf, R. R., Goossens, R. E., De Roover, B. P., and Borry, F. C.: Extraction of forest stand parameters from panchromatic and multispectral SPOT-1 data, Int. J. Remote Sens., 11, 1571-1588, https://doi.org/10.1080/01431169008955115, 1990.

Donchyts, G., Baart, F., Winsemius, H., Gorelick, N., Kwadijk, J., and Van De Giesen, N.: Earth's surface water change over the past 30 years, Nat. Clim. Change, 6, 810-813, https://doi.org/10.1038/nclimate3111, 2016.

Dorigo, W. A., Wagner, W., Hohensinn, R., Hahn, S., Paulik, C., Xaver, A., Gruber, A., Drusch, M., Mecklenburg, S., van Oevelen, P., Robock, A., and Jackson, T.: The International Soil Moisture Network: a data hosting facility for global in situ soil moisture measurements, Hydrol. Earth Syst. Sci., 15, 1675-1698, https://doi.org/10.5194/hess-15-1675-2011, 2011.

Dorigo, W. A., Gruber, A., De Jeu, R. A. M., Wagner, W., Stacke, T., Loew, A., Albergel, C., Brocca, L., Chung, D., Parinussa, R. M., and Kidd, R.: Evaluation of the ESA CCI soil moisture product using ground-based observations, Remote Sens. Environ., 162, 380-395, https://doi.org/10.1016/j.rse.2014.07.023, 2015.

Doumounia, A., Gosset, M., Cazenave, F., Kacou, M., and Zougmore, F.: Rainfall monitoring based on microwave links from cellular telecommunication networks: First results from a West African test bed, Geophys. Res. Lett., 41, 6016-6022, https://doi.org/10.1002/2014GL060724, 2014.

Drüe, C., Frey, W., Hoff, A., and Hauf, T.: Aircraft typespecific errors in AMDAR weather reports from commercial aircraft, Q. J. Roy. Meteorol. Soc., 134, 229-239, https://doi.org/10.1002/qj.205, 2008.
Drusch, M., Del Bello, U., Carlier, S., Colin, O., Fernandez, V., Gascon, F., Hoersch, B., Isola, C., Laberinti, P., Martimort, P., Meygret, A., Spoto, F., Sy, O., Marchese, F., and Bargellini, P.: Sentinel-2: ESA's Optical High-Resolution Mission for GMES Operational Services, Remote Sens. Environ., 120, 25-36, https://doi.org/10.1016/j.rse.2011.11.026, 2012.

Edberg, S. J., Evans, D. L., Graf, J. E., Hyon, J. J., Rosen, P. A., and Waliser, D. E.: Studying Earth in the New Millennium: NASA Jet Propulsion Laboratory's Contributions to Earth Science and Applications Space Agencies, IEEE Geosci. Remote Sens. Mag., 4, 26-39, https://doi.org/10.1109/MGRS.2016.2525678, 2016.

Elefante, S., Wagner, W., Briese, C., Cao, S., and Naeimi, V.: High-performance computing for soil moisture estimation, in: Proceedings of the 2016 conference on Big Data from Space (BiDS'16), Santa Cruz de Tenerife, Spain, 2016.

Entekhabi, D., Njoku, E. G., O’Neill, P. E., Kellogg, K. H., Crow, W. T., Edelstein, W. N., Entin, J. K., Goodman, S. D., Jackson, T. J., Johnson, J., Kimball, J., Piepmeier, J. R., Koster, R. D., Martin, N., McDonald, K. C., Moghaddam, M., Moran, S., Reichle, R., Shi, J. C., Spencer, M. W., Thurman, S. W., Tsang, L., and Van Zyl, J.: The soil moisture active passive (SMAP) mission, Proc. IEEE, 98, 704-716, https://doi.org/10.1109/JPROC.2010.2043918, 2010.

Ershadi, A., McCabe, M. F., Evans, J. P., and Walker, J. P.: Effects of spatial aggregation on the multi-scale estimation of evapotranspiration, Remote Sens. Environ., 131, 51-62, https://doi.org/10.1016/j.rse.2012.12.007, 2013.

Ershadi, A., McCabe, M. F., Evans, J. P., Chaney, N. W., and Wood, E. F.: Multi-site evaluation of terrestrial evaporation models using FLUXNET data, Agr. Forest Meteorol., 187, 46-61, https://doi.org/10.1016/j.agrformet.2013.11.008, 2014.

Everitt, J. H., Escobar, D. E., and Noriega, J.: A high resolution multispectral video system, Geocarto Int., 6, 45-51, https://doi.org/10.1080/10106049109354339, 1991.

Faghmous, J. H. and Kumar, V.: A Big Data Guide to Understanding Climate Change: The Case for Theory-Guided Data Science, Big Data, 2, 155-163, https://doi.org/10.1089/big.2014.0026, 2014.

Fekete, B. M., Looser, U., Pietroniro, A., and Robarts, R. D.: Rationale for Monitoring Discharge on the Ground, J. Hydrometeorol., 13, 1977-1986, https://doi.org/10.1175/jhm-d-11-0126.1, 2012.

Feng, Q., Liu, J., and Gong, J.: Urban Flood Mapping Based on Unmanned Aerial Vehicle Remote Sensing and Random Forest Classifier - A Case of Yuyao, China, Water, 7, 1437-1455, 2015.

Fisher, J. B., Tu, K. P., and Baldocchi, D. D.: Global estimates of the land-atmosphere water flux based on monthly AVHRR and ISLSCP-II data, validated at 16 FLUXNET sites, Remote Sens. Environ., 112, 901-919, https://doi.org/10.1016/j.rse.2007.06.025, 2008.

Fleming, R. J.: The Use of Commercial Aircraft as Platforms for Environmental Measurements, B. Am. Meteorol. Soc., 77, 2229-2242, https://doi.org/10.1175/15200477(1996)077<2229:tuocaa>2.0.co;2, 1996.

Flying Aquila: Early lessons from the first full-scale test flight and the path ahead: https://code.facebook.com/posts/ 268598690180189, last access: 10 November 2016.

Frankenberg, C., Fisher, J. B., Worden, J., Badgley, G., Saatchi, S. S., Lee, J.-E., Toon, G. C., Butz, A., Jung, M., Kuze, A., and Yokota, T.: New global observations of the terrestrial carbon cycle from GOSAT: Patterns of plant fluorescence with 
gross primary productivity, Geophys. Res. Lett., 38, L17706, https://doi.org/10.1029/2011GL048738, 2011.

Franz, T. E., Wang, T., Avery, W., Finkenbiner, C., and Brocca, L.: Combined analysis of soil moisture measurements from roving and fixed cosmic ray neutron probes for multiscale real-time monitoring, Geophys. Res. Lett., 42, 3389-3396, https://doi.org/10.1002/2015GL063963, 2015.

Giardino, C., Brando, V. E., Dekker, A. G., Strömbeck, N., and Candiani, G.: Assessment of water quality in Lake Garda (Italy) using Hyperion, Remote Sens. Environ., 109, 183-195, https://doi.org/10.1016/j.rse.2006.12.017, 2007.

Gorelick, N.: Google Earth Engine, European Geophysical Union, 7-12 April 2013, Vienna, Austria, 2013.

Gosset, M., Kunstmann, H., Zougmore, F., Cazenave, F., Leijnse, H., Uijlenhoet, R., Chwala, C., Keis, F., Doumounia, A., Boubacar, B., Kacou, M., Alpert, P., Messer, H., Rieckermann, J., and Hoedjes, J.: Improving Rainfall Measurement in Gauge Poor Regions Thanks to Mobile Telecommunication Networks, B. Am. Meteorol. Soc., 97, ES49-ES51, https://doi.org/10.1175/bams-d-15-00164.1, 2016.

Green, R. O., Eastwood, M. L., Sarture, C. M., Chrien, T. G., Aronsson, M., Chippendale, B. J., Faust, J. A., Pavri, B. E., Chovit, C. J., Solis, M., Olah, M. R., and Williams, O.: Imaging spectroscopy and the Airborne Visible/Infrared Imaging Spectrometer (AVIRIS), Remote Sens. Environ., 65, 227-248, https://doi.org/10.1016/S0034-4257(98)00064-9, 1998.

Haddad, Z. S., Peral, E., Tanelli, S., Sy, O., and Stephens, G.: RaInCube: A proposed constellation of atmospheric profiling radars in cubesat, Proc. SPIE, 9876, 987606, https://doi.org/doi:10.1117/12.2228188, 2016.

Hall, D. K., Riggs, G. A., and Salomonson, V. V.: Development of methods for mapping global snow cover using moderate resolution imaging spectroradiometer data, Remote Sens. Environ., 54, 127-140, https://doi.org/10.1016/0034-4257(95)00137-P, 1995.

Han, F., Zhang, Z., Wang, Z., Zhang, S., Liang, Y., and Chen, Y.: Real-time earth observation system based on Micro-Nano networks, Proceedings of the International Astronautical Congress, IAC, 12-16 October 2015, Jerusalem, Israel, 3271-3278, 2015.

Hashem, I. A. T., Yaqoob, I., Anuar, N. B., Mokhtar, S., Gani, A., and Ullah Khan, S.: The rise of "big data" on cloud computing: Review and open research issues, Inform. Syst., 47, 98-115, https://doi.org/10.1016/j.is.2014.07.006, 2015.

Hauser, D., Glennie, C., and Brooks, B.: Calibration and accuracy analysis of a low-cost mapping-grade mobile laser scanning system, J. Surv. Eng., 142, 04016011, https://doi.org/10.1061/(ASCE)SU.1943-5428.0000178, 2016.

Heimann, M. and Reichstein, M.: Terrestrial ecosystem carbon dynamics and climate feedbacks, Nature, 451, 289-292, 2008.

Heistermann, M., Jacobi, S., and Pfaff, T.: Technical Note: An open source library for processing weather radar data (wradlib), Hydrol. Earth Syst. Sci., 17, 863-871, https://doi.org/10.5194/hess17-863-2013, 2013.

Herrick, J. E., Karl, J. W., McCord, S. E., Buenemann, M., Riginos, C., Courtright, E., Van Zee, J., Ganguli, A. C., Angerer, J., Brown, J. R., Kimiti, D. W., Saltzman, R., Beh, A., and Bestelmeyer, B.: Two New Mobile Apps for Rangeland Inventory and Monitoring by Landowners and Land Managers, Rangelands, 39, 46-55, https://doi.org/10.1016/j.rala.2016.12.003, 2017.
Hevner, R., Puig-Suari, J., and Twiggs, R.: An advanced standard for CubeSats, in: Paper SSC11-II-13, 25th Annual AIAA/USU Conference on Small Satellites, Logan, UT, 2011.

Hidalgo, H. G., Das, T., Dettinger, M. D., Cayan, D. R., Pierce, D. W., Barnett, T. P., Bala, G., Mirin, A., Wood, A. W., Bonfils, C., Santer, B. D., and Nozawa, T.: Detection and attribution of streamflow timing changes to climate change in the Western United States, J. Climate, 22, 3838-3855, https://doi.org/10.1175/2009JCLI2470.1, 2009.

Hoffmann, H., Nieto, H., Jensen, R., Guzinski, R., Zarco-Tejada, P., and Friborg, T.: Estimating evaporation with thermal UAV data and two-source energy balance models, Hydrol. Earth Syst. Sci., 20, 697-713, https://doi.org/10.5194/hess-20-697-2016, 2016.

Houborg, R. and McCabe, M. F.: High-Resolution NDVI from Planet's Constellation of Earth Observing Nano-Satellites: A New Data Source for Precision Agriculture, Remote Sens., 8, 768, https://doi.org/10.3390/rs8090768, 2016.

Houborg, R., Fisher, J. B., and Skidmore, A. K.: Advances in remote sensing of vegetation function and traits, Int. J. Appl. Earth Obs. Geoinf., 43, 1-6, https://doi.org/10.1016/j.jag.2015.06.001, 2015.

Irons, J. R., Dwyer, J. L., and Barsi, J. A.: The next Landsat satellite: The Landsat Data Continuity Mission, Remote Sens. Environ., 122, 11-21, https://doi.org/10.1016/j.rse.2011.08.026, 2012.

Jana, R. B., Ershadi, A., and McCabe, M. F.: Examining the relationship between intermediate-scale soil moisture and terrestrial evaporation within a semi-arid grassland, Hydrol. Earth Syst. Sci., 20, 3987-4004, https://doi.org/10.5194/hess-20-3987-2016, 2016.

Jasinski, M. F., Stoll, J. D., Cook, W. B., Ondrusek, M., Stengel, E., and Brunt, K.: Inland and Near-Shore Water Profiles Derived from the High-Altitude Multiple Altimeter Beam Experimental Lidar (MABEL), J. Coast. Res., 76, 44-55, https://doi.org/10.2112/si76-005, 2016.

Jha, S. K., Mariethoz, G., Evans, J. P., and McCabe, M. F.: Demonstration of a geostatistical approach to physically consistent downscaling of climate modeling simulations, Water Resour. Res., 49, 245-259, https://doi.org/10.1029/2012WR012602, 2013.

Jung, M., Reichstein, M., and Bondeau, A.: Towards global empirical upscaling of FLUXNET eddy covariance observations: validation of a model tree ensemble approach using a biosphere model, Biogeosciences, 6, 2001-2013, https://doi.org/10.5194/bg-6-2001-2009, 2009.

Kalma, J., McVicar, T., and McCabe, M.: Estimating Land Surface Evaporation: A Review of Methods Using Remotely Sensed Surface Temperature Data, Surv. Geophys., 29, 421-469, 2008.

Kidd, C.: Satellite rainfall climatology: a review, Int. J. Climatol., 21, 1041-1066, https://doi.org/10.1002/joc.635, 2001.

Kidd, C. and Huffman, G. J.: Global precipitation measurement, Meteorol. Appl., 18, 334-353, https://doi.org/10.1002/met.284, 2011.

Kimball, J. S., McDonald, K. C., Keyser, A. R., Frolking, S., and Running, S. W.: Application of the NASA Scatterometer (NSCAT) for Determining the Daily Frozen and Nonfrozen Landscape of Alaska, Remote Sens. Environ., 75, 113-126, https://doi.org/10.1016/S0034-4257(00)00160-7, 2001.

King, D. J.: Airborne multispectral digital camera and video sensors: A critical review of system designs 
and applications, Can. J. Remote Sens., 21, 245-273, https://doi.org/10.1080/07038992.1995.10874621, 1995.

Klemeš, V.: Dilettantism in hydrology: Transition or destiny?, Water Resour. Res., 22, 177S-188S, https://doi.org/10.1029/WR022i09Sp0177S, 1986.

Koch, J., Jensen, K. H., and Stisen, S.: Toward a true spatial model evaluation in distributed hydrological modeling: Kappa statistics, Fuzzy theory, and EOF-analysis benchmarked by the human perception and evaluated against a modeling case study, Water Resour. Res., 51, 1225-1246, https://doi.org/10.1002/2014WR016607, 2015.

Kursinski, E. R., Hajj, G. A., Schofield, J. T., Linfield, R. P., and Hardy, K. R.: Observing Earth's atmosphere with radio occultation measurements using the Global Positioning System, J. Geophys. Res.-Atmos., 102, 23429-23465, https://doi.org/10.1029/97JD01569, 1997.

Lanfear, K. J. and Hirsch, R. M.: USGS study reveals a decline in long-record streamgages, Eos, 80, 605-607, https://doi.org/10.1029/99EO00406, 1999.

Larson, K. M., Small, E. E., Gutmann, E. D., Bilich, A. L., Braun, J. J., and Zavorotny, V. U.: Use of GPS receivers as a soil moisture network for water cycle studies, Geophys. Res. Lett., 35, L24405, https://doi.org/10.1029/2008GL036013, 2008.

Larson, K. M., Gutmann, E. D., Zavorotny, V. U., Braun, J. J., Williams, M. W., and Nievinski, F. G.: Can we measure snow depth with GPS receivers?, Geophys. Res. Lett., 36, L17502, https://doi.org/10.1029/2009GL039430, 2009.

Lary, D. J., Alavi, A. H., Gandomi, A. H., and Walker, A. L.: Machine learning in geosciences and remote sensing, Geosci. Front., 7, 3-10, https://doi.org/10.1016/j.gsf.2015.07.003, 2016.

Le Coz, J., Patalano, A., Collins, D., Guillén, N. F., García, C. M., Smart, G. M., Bind, J., Chiaverini, A., Le Boursicaud, R., Dramais, G., and Braud, I.: Crowdsourced data for flood hydrology: Feedback from recent citizen science projects in Argentina, France and New Zealand, J. Hydrol., 541, 766-777, https://doi.org/10.1016/j.jhydrol.2016.07.036, 2016.

Lee, Y. R., Shin, D. B., Kim, J. H., and Park, H. S.: Precipitation estimation over radar gap areas based on satellite and adjacent radar observations, Atmos. Meas. Tech., 8, 719-728, https://doi.org/10.5194/amt-8-719-2015, 2015.

Leijnse, H., Uijlenhoet, R., and Stricker, J. N. M.: Rainfall measurement using radio links from cellular communication networks, Water Resour. Res., 43, W03201, https://doi.org/10.1029/2006WR005631, 2007.

Lethbridge, M.: Precipitation probability and satellite radiation data, Mon. Weather Rev., 95, 487-490, https://doi.org/10.1175/15200493(1967)095<0487:ppasrd>2.3.co;2, 1967.

Lettenmaier, D. P., Alsdorf, D., Dozier, J., Huffman, G. J., Pan, M., and Wood, E. F.: Inroads of remote sensing into hydrologic science during the WRR era, Water Resour. Res., 51, 7309-7342, https://doi.org/10.1002/2015WR017616, 2015.

Li, F., Crow, W. T., and Kustas, W. P.: Towards the estimation root-zone soil moisture via the simultaneous assimilation of thermal and microwave soil moisture retrievals, Adv. Water Resour., 33, 201-214, https://doi.org/10.1016/j.advwatres.2009.11.007, 2010.

Liu, L., Zhang, T., and Wahr, J.: InSAR measurements of surface deformation over permafrost on the North Slope of Alaska, J. Geophys. Res.-Earth Surf., 115, F03023, https://doi.org/10.1029/2009JF001547, 2010.

Liu, Y. Y., de Jeu, R. A. M., McCabe, M. F., Evans, J. P., and van Dijk, A. I. J. M.: Global long-term passive microwave satellite-based retrievals of vegetation optical depth, Geophys. Res. Lett., 38, L18402, https://doi.org/10.1029/2011GL048684, 2011a.

Liu, Y. Y., Parinussa, R. M., Dorigo, W. A., De Jeu, R. A. M., Wagner, W., van Dijk, A. I. J. M., McCabe, M. F., and Evans, J. P.: Developing an improved soil moisture dataset by blending passive and active microwave satellite-based retrievals, Hydrol Earth Syst. Sci., 15, 425-436, https://doi.org/10.5194/hess-15425-2011, $2011 b$.

Liu, Y. Y., Dorigo, W. A., Parinussa, R. M., De Jeu, R. A. M., Wagner, W., McCabe, M. F., Evans, J. P., and Van Dijk, A. I. J. M.: Trend-preserving blending of passive and active microwave soil moisture retrievals, Remote Sens. Environ., 123, 280-297, 2012.

Liu, Y. Y., van Dijk, A. I. J. M., McCabe, M. F., Evans, J. P., and de Jeu, R. A. M.: Global vegetation biomass change (1988-2008) and attribution to environmental and human drivers, Global Ecol. Biogeogr., 22, 692-705, 2013.

Liu, Y. Y., Van Dijk, A. I. J. M., De Jeu, R. A. M., Canadell, J. G., McCabe, M. F., Evans, J. P., and Wang, G.: Recent reversal in loss of global terrestrial biomass, Nat. Clim. Change, 5, 470 474, https://doi.org/10.1038/nclimate2581, 2015.

López, O., Houborg, R., and McCabe, M. F.: Evaluating the hydrological consistency of evaporation products using satellite-based gravity and rainfall data, Hydrol. Earth Syst. Sci., 21, 323-343, https://doi.org/10.5194/hess-21-323-2017, 2017.

Lorenz, C. and Kunstmann, H.: The hydrological cycle in three state-of-the-art reanalyses: Intercomparison and performance analysis, J. Hydrometeorol., 13, 1397-1420, https://doi.org/10.1175/JHM-D-11-088.1, 2012.

Mace, G. G., Zhang, Q., Vaughan, M., Marchand, R., Stephens, G., Trepte, C., and Winker, D.: A description of hydrometeor layer occurrence statistics derived from the first year of merged Cloudsat and CALIPSO data, J. Geophys. Res.-Atmos., 114, D00A26, https://doi.org/10.1029/2007JD009755, 2009.

McCabe, M. F., Franks, S. W., and Kalma, J. D.: Calibration of a land surface model using multiple data sets, J. Hydrol., 302, 209 222, https://doi.org/10.1016/j.jhydrol.2004.07.002, 2005.

McCabe, M. F., Wood, E. F., Wójcik, R., Pan, M., Sheffield, J., Gao, H., and Su, H.: Hydrological consistency using multi-sensor remote sensing data for water and energy cycle studies, Remote Sens. Environ., 112, 430-444, https://doi.org/10.1016/j.rse.2007.03.027, 2008.

McCabe, M. F., Ershadi, A., Jimenez, C., Miralles, D. G., Michel, D., and Wood, E. F.: The GEWEX LandFlux project: evaluation of model evaporation using tower-based and globally gridded forcing data, Geosci. Model Dev., 9, 283-305, https://doi.org/10.5194/gmd-9-283-2016, 2016.

McGuire, M. P., Roberge, M. C., and Lian, J.: HydroCloud: A cloud-based system for hydrologic data integration and analysis, in: Proceedings - 5th International Conference on Computing for Geospatial Research and Application, COM.Geo 2014, 4-6 August 2014, Washington, D.C., USA, 9-16, 2014.

Mecklenburg, S., Drusch, M., Kaleschke, L., Rodriguez-Fernandez, N., Reul, N., Kerr, Y., Font, J., Martin-Neira, M., Oliva, R., Daganzo-Eusebio, E., Grant, J. P., Sabia, R., Macel- 
loni, G., Rautiainen, K., Fauste, J., de Rosnay, P., MunozSabater, J., Verhoest, N., Lievens, H., Delwart, S., Crapolicchio, R., de la Fuente, A., and Kornberg, M.: ESA's Soil Moisture and Ocean Salinity mission: From science to operational applications, Remote Sens. Environ., 180, 3-18, https://doi.org/10.1016/j.rse.2015.12.025, 2016.

Merlin, O., Al Bitar, A., Walker, J. P., and Kerr, Y.: An improved algorithm for disaggregating microwave-derived soil moisture based on red, near-infrared and thermalinfrared data, Remote Sens. Environ., 114, 2305-2316, https://doi.org/10.1016/j.rse.2010.05.007, 2010.

Meroni, M., Rossini, M., Guanter, L., Alonso, L., Rascher, U., Colombo, R., and Moreno, J.: Remote sensing of solar-induced chlorophyll fluorescence: Review of methods and applications, Remote Sens. Environ., 113, 2037-2051, https://doi.org/10.1016/j.rse.2009.05.003, 2009.

Messer, H., Zinevich, A., and Alpert, P.: Environmental Monitoring by Wireless Communication Networks, Science, 312, 713, 2006.

Miralles, D. G., De Jeu, R. A. M., Gash, J. H., Holmes, T. R. H., and Dolman, A. J.: Magnitude and variability of land evaporation and its components at the global scale, Hydrol. Earth Syst. Sci., 15, 967-981, https://doi.org/10.5194/hess-15-967-2011, 2011.

Miralles, D. G., van den Berg, M. J., Gash, J. H., Parinussa, R. M., de Jeu, R. A. M., Beck, H. E., Holmes, T. R. H., Jiménez, C., Verhoest, N. E. C., Dorigo, W. A., Teuling, A. J., and Johannes Dolman, A.: El Niño-La Niña cycle and recent trends in continental evaporation, Nat. Clim. Change, 4, 122-126, https://doi.org/10.1038/nclimate2068, 2014.

Miralles, D. G., Jiménez, C., Jung, M., Michel, D., Ershadi, A., McCabe, M. F., Hirschi, M., Martens, B., Dolman, A. J., Fisher, J. B., Mu, Q., Seneviratne, S. I., Wood, E. F., and Fernández-Prieto, D.: The WACMOS-ET project - Part 2: Evaluation of global terrestrial evaporation data sets, Hydrol. Earth Syst. Sci., 20, 823842, https://doi.org/10.5194/hess-20-823-2016, 2016.

Mladenova, I. E., Jackson, T. J., Njoku, E., Bindlish, R., Chan, S., Cosh, M. H., Holmes, T. R. H., de Jeu, R. A. M., Jones, L., Kimball, J., Paloscia, S., and Santi, E.: Remote monitoring of soil moisture using passive microwave-based techniques - Theoretical basis and overview of selected algorithms for AMSR-E, Remote Sens. Environ., 144, 197-213, https://doi.org/10.1016/j.rse.2014.01.013, 2014.

Moghaddam, M., Rahmat-Samii, Y., Rodriguez, E., Entekhabi, D., Hoffman, J., Moller, D., Pierce, L. E., Saatchi, S., and Thomson, M.: Microwave Observatory of Subcanopy and Subsurface (MOSS): A Mission Concept for Global Deep Soil Moisture Observations, IEEE T. Geosci. Remote, 45, 2630-2643, https://doi.org/10.1109/TGRS.2007.898236, 2007.

Montzka, C., Bogena, H., Zreda, M., Monerris, A., Morrison, R., Muddu, S., and Vereecken, H.: Validation of Spaceborne and Modelled Surface Soil Moisture Products with Cosmic-Ray Neutron Probes, Remote Sens., 9, 103, 2017.

Mueller, B., Hirschi, M., Jimenez, C., Ciais, P., Dirmeyer, P. A., Dolman, A. J., Fisher, J. B., Jung, M., Ludwig, F., Maignan, F., Miralles, D. G., McCabe, M. F., Reichstein, M., Sheffield, J., Wang, K., Wood, E. F., Zhang, Y., and Seneviratne, S. I.: Benchmark products for land evapotranspiration: LandFluxEVAL multi-data set synthesis, Hydrol. Earth Syst. Sci., 17, 3707-3720, https://doi.org/10.5194/hess-17-3707-2013, 2013.
Muller, C. L., Chapman, L., Johnston, S., Kidd, C., Illingworth, S., Foody, G., Overeem, A., and Leigh, R. R.: Crowdsourcing for climate and atmospheric sciences: current status and future potential, Int. J. Climatol., 35, 3185-3203, https://doi.org/10.1002/joc.4210, 2015.

Müller, M. F., Yoon, J., Gorelick, S. M., Avisse, N., and Tilmant, A.: Impact of the Syrian refugee crisis on land use and transboundary freshwater resources, P. Natl. Acad. Sci. USA, 113, 14932-14937, 2016.

Murthy, K., Shearn, M., Smiley, B. D., Chau, A. H., Levine, J., and Robinson, M. D.: Skysat-1: Very high-resolution imagery from a small satellite, Proc. SPIE, 9241, 92411E, https://doi.org/10.1117/12.2074163, 2014.

Naeimi, V., Scipal, K., Bartalis, Z., Hasenauer, S., and Wagner, W.: An Improved Soil Moisture Retrieval Algorithm for ERS and METOP Scatterometer Observations, IEEE T. Geosci. Remote, 47, 1999-2013, https://doi.org/10.1109/TGRS.2008.2011617, 2009.

Nagy, G. and Nagy, G.: Digital image-processing activities in remote sensing for earth resources, Proc. IEEE, 60, 1177-1200, https://doi.org/10.1109/PROC.1972.8879, 1972.

NASA: CubeSat Launch Initiative, https://www.nasa.gov/ directorates/heo/home/CubeSats_initiative/ (last access: 10 November 2016), 2016a.

NASA: Small Spacecraft Technology Program: https://www.nasa. gov/directorates/spacetech/small_spacecraft/index.html (last access: 10 November 2016), 2016 b.

National Research Council: Earth Science and Applications From Space: National Imperatives for the Next Decade and Beyond, Earth Science and Applications from Space: National Imperatives for the Next Decade and Beyond, National Academies Press, Washington, D.C., 400 pp., 2007.

Niu, G.-Y., Seo, K.-W., Yang, Z.-L., Wilson, C., Su, H., Chen, J., and Rodell, M.: Retrieving snow mass from GRACE terrestrial water storage change with a land surface model, Geophys. Res. Lett., 34, L15704, https://doi.org/10.1029/2007GL030413, 2007.

Njoku, E. G. and Entekhabi, D.: Passive microwave remote sensing of soil moisture, J. Hydrol., 184, 101-129, 1996.

Njoku, E. G. and Li, L.: Retrieval of land surface parameters using passive microwave measurements at 6-18 GHz, IEEE T. Geosci. Remote, 37, 79-93, https://doi.org/10.1109/36.739125, 1999.

Nordberg, W.: Geophysical observations from Nimbus I, Science, 150, 559-572, 1965.

Ochoa-Rodriguez, S., Wang, L. P., Gires, A., Pina, R. D., ReinosoRondinel, R., Bruni, G., Ichiba, A., Gaitan, S., Cristiano, E., Van Assel, J., Kroll, S., Murlà-Tuyls, D., Tisserand, B., Schertzer, D., Tchiguirinskaia, I., Onof, C., Willems, P., and Ten Veldhuis, M. C.: Impact of spatial and temporal resolution of rainfall inputs on urban hydrodynamic modelling outputs: A multi-catchment investigation, J. Hydrol., 531, 389-407, https://doi.org/10.1016/j.jhydrol.2015.05.035, 2015.

Odermatt, D., Gitelson, A., Brando, V. E., and Schaepman, M.: Review of constituent retrieval in optically deep and complex waters from satellite imagery, Remote Sens. Environ., 118, 116126, https://doi.org/10.1016/j.rse.2011.11.013, 2012.

Overeem, A., Leijnse, H., and Uijlenhoet, R.: Countrywide rainfall maps from cellular communication networks, P. Natl. Acad. Sci. USA, 110, 2741-2745, https://doi.org/10.1073/pnas.1217961110, 2013a. 
Overeem, A., Robinson, J. C. R., Leijnse, H., Steeneveld, G. J., Horn, B. K. P., and Uijlenhoet, R.: Crowdsourcing urban air temperatures from smartphone battery temperatures, Geophys. Res. Lett., 40, 4081-4085, https://doi.org/10.1002/grl.50786, 2013b.

Overeem, A., Leijnse, H., and Uijlenhoet, R.: Two and a half years of country-wide rainfall maps using radio links from commercial cellular telecommunication networks, Water Resour. Res., 52, 8039-8065, https://doi.org/10.1002/2016WR019412, 2016.

Paloscia, S., Pettinato, S., Santi, E., Notarnicola, C., Pasolli, L., and Reppucci, A.: Soil moisture mapping using Sentinel-1 images: Algorithm and preliminary validation, Remote Sens. Environ., 134, 234-248, https://doi.org/10.1016/j.rse.2013.02.027, 2013.

Pan, M., Cai, X., Chaney, N. W., Entekhabi, D., and Wood, E. F.: An initial assessment of SMAP soil moisture retrievals using high-resolution model simulations and in situ observations, Geophys. Res. Lett., 43, 9662-9668, https://doi.org/10.1002/2016GL069964, 2016.

Papagiannopoulou, C., Miralles, D. G., Decubber, S., Demuzere, M., Verhoest, N. E. C., Dorigo, W. A., and Waegeman, W.: A non-linear Granger-causality framework to investigate climatevegetation dynamics, Geosci. Model Dev., 10, 1945-1960, https://doi.org/10.5194/gmd-10-1945-2017, 2017.

Petersen, R. A.: On the Impact and Benefits of AMDAR Observations in Operational Forecasting - Part I: A Review of the Impact of Automated Aircraft Wind and Temperature Reports, B. Am. Meteorol. Soc., 97, 585-602, https://doi.org/10.1175/bamsd-14-00055.1, 2016.

Peters-Lidard, C. D., Clark, M., Samaniego, L., Verhoest, N. E. C., van Emmerik, T., Uijlenhoet, R., Achieng, K., Franz, T. E., and Woods, R.: Scaling, similarity, and the fourth paradigm for hydrology, Hydrol. Earth Syst. Sci., 21, 3701-3713, https://doi.org/10.5194/hess-21-3701-2017, 2017.

Planet Team: Planet Application Program Interface: In Space for Life on Earth, San Francisco, CA, 2017.

Prata, A. J., Dezitter, F., Davies, I., Weber, K., Birnfeld, M., Moriano, D., Bernardo, C., Vogel, A., Prata, G. S., Mather, T. A., Thomas, H. E., Cammas, J., and Weber, M.: Artificial cloud test confirms volcanic ash detection using infrared spectral imaging, Scient. Rep., 6, 25620, https://doi.org/10.1038/srep25620, 2016.

Puig-Suari, J., Turner, C., and Ahlgren, W.: Development of the standard CubeSat deployer and a CubeSat class picosatellite, in: IEEE Aerospace Conference Proceedings, 10-17 March 2001, Big Sky, MO, USA, 1347-1353, 2001.

Rabiei, E., Haberlandt, U., Sester, M., Fitzner, D., and Wallner, M.: Areal rainfall estimation using moving cars - computer experiments including hydrological modeling, Hydrol. Earth Syst. Sci., 20, 3907-3922, https://doi.org/10.5194/hess-20-3907-2016, 2016.

Rasouli, K., Hsieh, W. W., and Cannon, A. J.: Daily streamflow forecasting by machine learning methods with weather and climate inputs, J. Hydrol., 414-415, 284-293, https://doi.org/10.1016/j.jhydrol.2011.10.039, 2012.

Rautiainen, K., Parkkinen, T., Lemmetyinen, J., Schwank, M., Wiesmann, A., Ikonen, J., Derksen, C., Davydov, S., Davydova, A., Boike, J., Langer, M., Drusch, M., and Pulliainen, J.: SMOS prototype algorithm for detecting autumn soil freezing, Remote Sens. Environ., 180, 346-360, https://doi.org/10.1016/j.rse.2016.01.012, 2016.
Reges, H. W., Doesken, N., Turner, J., Newman, N., Bergantino, A., and Schwalbe, Z.: CoCoRaHS: The Evolution and Accomplishments of a Volunteer Rain Gauge Network, B. Am. Meteorol. Soc., 97, 1831-1846, https://doi.org/10.1175/BAMS-D-1400213.1, 2016.

Reichle, R. H., Koster, R. D., Liu, P., Mahanama, S. P. P., Njoku, E. G., and Owe, M.: Comparison and assimilation of global soil moisture retrievals from the Advanced Microwave Scanning Radiometer for the Earth Observing System (AMSR-E) and the Scanning Multichannel Microwave Radiometer (SMMR), J. Geophys. Res.-Atmos., 112, D09108, https://doi.org/10.1029/2006JD008033, 2007.

Rios Gaona, M. F., Overeem, A., Leijnse, H., and Uijlenhoet, R.: First-year evaluation of GPM rainfall over the Netherlands: IMERG day 1 final run (V03D), J. Hydrometeorol., 17, 27992814, https://doi.org/10.1175/JHM-D-16-0087.1, 2016.

Roberts, D. A., Quattrochi, D. A., Hulley, G. C., Hook, S. J., and Green, R. O.: Synergies between VSWIR and TIR data for the urban environment: An evaluation of the potential for the Hyperspectral Infrared Imager (HyspIRI) Decadal Survey mission, Remote Sens. Environ., 117, 83-101, https://doi.org/10.1016/j.rse.2011.07.021, 2012.

Rodell, M. and Famiglietti, J. S.: Detectability of variations in continental water storage from satellite observations of the time dependent gravity field, Water Resour. Res., 35, 2705-2723, https://doi.org/10.1029/1999WR900141, 1999.

Rodell, M., Chen, J., Kato, H., Famiglietti, J. S., Nigro, J., and Wilson, C. R.: Estimating groundwater storage changes in the Mississippi River basin (USA) using GRACE, Hydrogeol. J., 15, 159-166, 10.1007/s10040-006-0103-7, 2007.

Rodríguez-Fernández, N., Kerr, Y., van der Schalie, R., Al-Yaari, A., Wigneron, J.-P., de Jeu, R., Richaume, P., Dutra, E., Mialon, A., and Drusch, M.: Long Term Global Surface Soil Moisture Fields Using an SMOS-Trained Neural Network Applied to AMSR-E Data, Remote Sens., 8, 959, 2016.

Roy, D. P., Ju, J., Lewis, P., Schaaf, C., Gao, F., Hansen, M., and Lindquist, E.: Multi-temporal MODIS-Landsat data fusion for relative radiometric normalization, gap filling, and prediction of Landsat data, Remote Sens. Environ., 112, 3112-3130, https://doi.org/10.1016/j.rse.2008.03.009, 2008.

Sabel, D., Bartsch, A., Schlaffer, S., Klein, J. P., and Wagner, W.: Soil moisture mapping in permafrost regions - An outlook to Sentinel-1, in: 2012 IEEE International Geoscience and Remote Sensing Symposium, 22-27 July 2012, Munich, Germany, 12161219, 2012.

Sanchez, P. A., Ahamed, S., Carré, F., Hartemink, A. E., Hempel, J., Huising, J., Lagacherie, P., McBratney, A. B., McKenzie, N. J., Mendonça-Santos, M. D. L., Minasny, B., Montanarella, L., Okoth, P., Palm, C. A., Sachs, J. D., Shepherd, K. D., Vågen, T.G., Vanlauwe, B., Walsh, M. G., Winowiecki, L. A., and Zhang, G.-L.: Digital Soil Map of the World, Science, 325, 680-681, https://doi.org/10.1126/science.1175084, 2009.

Schmugge, T. J., Kustas, W. P., Ritchie, J. C., Jackson, T. J., and Rango, A.: Remote sensing in hydrology, Adv. Water Resour., 25, 1367-1385, https://doi.org/10.1016/S0309-1708(02)000659, 2002.

Selva, D., and Krejci, D.: A survey and assessment of the capabilities of Cubesats for Earth observation, Acta Astronaut., 74, 50-68, https://doi.org/10.1016/j.actaastro.2011.12.014, 2012. 
Sharman, R. D., Cornman, L. B., Meymaris, G., Pearson, J., and Farrar, T.: Description and Derived Climatologies of Automated In Situ Eddy-Dissipation-Rate Reports of Atmospheric Turbulence, J. Appl. Meteorol. Clim., 53, 1416-1432, https://doi.org/10.1175/jamc-d-13-0329.1, 2014.

Shaw, J. A., Nugent, P. W., Kaufman, N. A., Pust, N. J., Mikes, D., Knierim, C., Faulconer, N., Larimer, R. M., Desjardins, A. C., and Knighton, W. B.: Multispectral imaging systems on tethered balloons for optical remote sensing education and research, J. Appl. Remote Sens., 6, 063613, https://doi.org/10.1117/1.JRS.6.063613, 2012.

Sheffield, J., Ferguson, C. R., Troy, T. J., Wood, E. F., and McCabe, M. F.: Closing the terrestrial water budget from satellite remote sensing, Geophys. Res. Lett., 36, L07403, https://doi.org/10.1029/2009GL037338, 2009.

Shiklomanov, A. I., Lammers, R. B., and Vörösmarty, C. J.: Widespread decline in hydrological monitoring threatens PanArctic research, Eos, 83, 13-17, 2002.

Small, E. E., Larson, K. M., and Braun, J. J.: Sensing vegetation growth with reflected GPS signals, Geophys. Res. Lett., 37, L12401, https://doi.org/10.1029/2010GL042951, 2010.

Solar Explorer 2: Solar Impulse 2 completes chemistry world tour: TCE The Chemical Engineer, Institution of Chemical Engineers, 13 pp., 2016.

Stahl, K., Hisdal, H., Hannaford, J., Tallaksen, L. M., van Lanen, H. A. J., Sauquet, E., Demuth, S., Fendekova, M., and Jódar, J.: Streamflow trends in Europe: evidence from a dataset of nearnatural catchments, Hydrol. Earth Syst. Sci., 14, 2367-2382, https://doi.org/10.5194/hess-14-2367-2010, 2010.

Steiner, M., Smith, J. A., Burges, S. J., Alonso, C. V., and Darden, R. W.: Effect of bias adjustment and rain gauge data quality control on radar rainfall estimation, Water Resour. Res., 35, 2487-2503, https://doi.org/10.1029/1999WR900142, 1999.

Stephens, G. L., Vane, D. G., Boain, R. J., Mace, G. G., Sassen, K., Wang, Z., Illingworth, A. J., O'Connor, E. J., Rossow, W. B., Durden, S. L., Miller, S. D., Austin, R. T., Benedetti, A., and Mitrescu, C.: The cloudsat mission and the A-Train: A new dimension of space-based observations of clouds and precipitation, B. Am. Meteorol. Soc., 83, 1771-1790, 2002.

Stisen, S., McCabe, M. F., Refsgaard, J. C., Lerer, S., and Butts, M. B.: Model parameter analysis using remotely sensed pattern information in a multi-constraint framework, J. Hydrol., 409, 337349, 2011.

Su, C.-H., Ryu, D., Dorigo, W., Zwieback, S., Gruber, A., Albergel, C., Reichle, R. H., and Wagner, W.: Homogeneity of a global multisatellite soil moisture climate data record, Geophys. Res. Lett., 43, 11245-11252, https://doi.org/10.1002/2016GL070458, 2016.

Swenson, S., Wahr, J., and Milly, P. C. D.: Estimated accuracies of regional water storage variations inferred from the Gravity Recovery and Climate Experiment (GRACE), Water Resour. Res., 39, 1223, https://doi.org/10.1029/2002WR001808, 2003.

Tang, Q., Gao, H., Lu, H., and Lettenmaier, D. P.: Remote sensing: Hydrology, Prog. Phys. Geogr., 33, 490-509, https://doi.org/10.1177/0309133309346650, 2009.

Tapley, B. D., Bettadpur, S., Ries, J. C., Thompson, P. F., and Watkins, M. M.: GRACE measurements of mass variability in the Earth system, Science, 305, 503-505, 2004.
Tollefson, J.: Race to provide commercial weather data heats up, Nature, 542, 18, https://doi.org/10.1038/542018a, 2017.

Townshend, J. R. G.: The spatial resolving power of earth resources satellites, Prog. Phys. Geogr., 5, 32-55, https://doi.org/10.1177/030913338100500102, 1981.

Turner, D., Lucieer, A., and Watson, C.: An automated technique for generating georectified mosaics from ultra-high resolution Unmanned Aerial Vehicle (UAV) imagery, based on Structure from Motion (SFM) point clouds, Remote Sens., 4, 1392-1410, https://doi.org/10.3390/rs4051392, 2012.

van de Giesen, N., Hut, R., and Selker, J.: The Trans-African HydroMeteorological Observatory (TAHMO), Wiley Interdisc. Rev. Water, 1, 341-348, https://doi.org/10.1002/wat2.1034, 2014.

Vander Jagt, B., Lucieer, A., Wallace, L., Turner, D., and Durand, M.: Snow Depth Retrieval with UAS Using Photogrammetric Techniques, Geosciences, 5, 264-285, 2015.

van Vliet, M. T. H., Franssen, W. H. P., Yearsley, J. R., Ludwig, F., Haddeland, I., Lettenmaier, D. P., and Kabat, P.: Global river discharge and water temperature under climate change, Global Environ. Change, 23, 450-464, https://doi.org/10.1016/j.gloenvcha.2012.11.002, 2013.

Vaughan, W. W. and Johnson, D. L.: Meteorological Satellites The Very Early Years Prior to Launch of TIROS-1, B. Am. Meteorol. Soc., 75, 2295-2302, https://doi.org/10.1175/15200477(1994)075<2295:MSVEYP>2.0.CO;2, 1994.

Vierling, L. A., Fersdahl, M., Chen, X., Li, Z., and Zimmerman, P.: The Short Wave Aerostat-Mounted Imager (SWAMI): A novel platform for acquiring remotely sensed data from a tethered balloon, Remote Sens. Environ., 103, 255-264, https://doi.org/10.1016/j.rse.2005.01.021, 2006.

Villien, A., Pedersen, G., Charvet, P., and Maliet, E.: Geostationary observation space surveillance system (GO3S) - Real time video from space, in: Proceedings of the International Astronautical Congress, IAC, 29 September-3 October 2014, Toronto, Canada, 2460-2464, 2014.

Vivoni, E. R., Rango, A., Anderson, C. A., Pierini, N. A., SchreinerMcgraw, A. P., Saripalli, S., and Laliberte, A. S.: Ecohydrology with unmanned aerial vehicles, Ecosphere, 5, 130, https://doi.org/10.1890/ES14-00217.1, 2014.

Wagner, W., Naeimi, V., Scipal, K., de Jeu, R., and Martínez-Fernández, J.: Soil moisture from operational meteorological satellites, Hydrogeol. J., 15, 121-131, https://doi.org/10.1007/s10040-006-0104-6, 2007.

Wagner, W., Hahn, S., Kidd, R., Melzer, T., Bartalis, Z., Hasenauer, S., Figa-Saldaña, J., De Rosnay, P., Jann, A., Schneider, S., Komma, J., Kubu, G., Brugger, K., Aubrecht, C., Züger, J., Gangkofner, U., Kienberger, S., Brocca, L., Wang, Y., Blöschl, G., Eitzinger, J., Steinnocher, K., Zeil, P., and Rubel, F.: The ASCAT soil moisture product: A review of its specifications, validation results, and emerging applications, Meteorol. Z., 22, 5-33, https://doi.org/10.1127/0941-2948/2013/0399, 2013.

Wagner, W., Fröhlich, J., Wotawa, G., Stowasser, R., Staudinger, M., Hoffmann, C., Walli, A., Federspiel, C., Aspetsberger, M., Atzberger, C., Briese, C., Notarnicola, C., Zebisch, M., Boresch, A., Enenkel, M., Kidd, R., von Beringe, A., Hasenauer, S., Naeimi, V., and Mücke, W.: Addressing Grand Challenges in Earth Observation Science: The Earth Observation Data Centre for Water Resources Monitoring, ISPRS 
Ann. Photogramm. Remote Sens. Spatial Inf. Sci., II-7, 81-88, https://doi.org/10.5194/isprsannals-II-7-81-2014, 2014.

Wang, K. and Dickinson, R. E.: A review of global terrestrial evapotranspiration: Observation, modeling, climatology, and climatic variability, Rev. Geophys., 50, RG2005, https://doi.org/10.1029/2011rg000373, 2012.

Warren, M. S., Brumby, S. P., Skillman, S. W., Kelton, T., Wohlberg, B., Mathis, M., Chartrand, R., Keisler, R., and Johnson, M.: Seeing the Earth in the Cloud: Processing one petabyte of satellite imagery in one day, in: 2015 IEEE Applied Imagery Pattern Recognition Workshop (AIPR), 14-16 October 2014, Washington, D.C., USA, 1-12, 2015.

Whitehead, P. G., Wilby, R. L., Battarbee, R. W., Kernan, M., and Wade, A. J.: A review of the potential impacts of climate change on surface water quality, Hydrolog. Sci. J., 54, 101-123, https://doi.org/10.1623/hysj.54.1.101, 2009.

Woellert, K., Ehrenfreund, P., Ricco, A. J., and Hertzfeld, H.: Cubesats: Cost-effective science and technology platforms for emerging and developing nations, Adv. Space Res., 47, 663-684, https://doi.org/10.1016/j.asr.2010.10.009, 2011.

Woo, M. K., Kane, D. L., Carey, S. K., and Yang, D.: Progress in permafrost hydrology in the new millennium, Permafrost Periglac. Process., 19, 237-254, https://doi.org/10.1002/ppp.613, 2008.

Wood, E. F., Roundy, J. K., Troy, T. J., van Beek, L. P. H., Bierkens, M. F. P., Blyth, E., de Roo, A., Döll, P., Ek, M., Famiglietti, J., Gochis, D., van de Giesen, N., Houser, P., Jaffé, P. R., Kollet, S., Lehner, B., Lettenmaier, D. P., Peters-Lidard, C., Sivapalan, M., Sheffield, J., Wade, A., and Whitehead, P.: Hyperresolution global land surface modeling: Meeting a grand challenge for monitoring Earth's terrestrial water, Water Resour. Res., 47, W05301, https://doi.org/10.1029/2010WR010090, 2011.

Wulder, M. A., White, J. C., Goward, S. N., Masek, J. G., Irons, J. R., Herold, M., Cohen, W. B., Loveland, T. R., and Woodcock, C. E.: Landsat continuity: Issues and opportunities for land cover monitoring, Remote Sensing of Environment, 112, 955969, https://doi.org/10.1016/j.rse.2007.07.004, 2008.

Wyche, S. and Steinfield, C.: Why Don't Farmers Use Cell Phones to Access Market Prices? Technology Affordances and Barriers to Market Information Services Adoption in Rural Kenya, Inform. Technol. Dev., 22, 320-333, https://doi.org/10.1080/02681102.2015.1048184, 2016.

Zacharias, S., Bogena, H., Samaniego, L., Mauder, M., Fuß, R., Pütz, T., Frenzel, M., Schwank, M., Baessler, C., ButterbachBahl, K., Bens, O., Borg, E., Brauer, A., Dietrich, P., Hajnsek, I., Helle, G., Kiese, R., Kunstmann, H., Klotz, S., Munch, J. C., Papen, H., Priesack, E., Schmid, H. P., Steinbrecher, R., Rosenbaum, U., Teutsch, G., and Vereecken, H.: A network of terrestrial environmental observatories in Germany, Vadose Zone J., 10, 955-973, https://doi.org/10.2136/vzj2010.0139, 2011.
Zaitchik, B. F., Rodell, M., and Reichle, R. H.: Assimilation of GRACE Terrestrial Water Storage Data into a Land Surface Model: Results for the Mississippi River Basin, J. Hydrometeorol., 9, 535-548, https://doi.org/10.1175/2007jhm951.1, 2008.

Zarco-Tejada, P. J., González-Dugo, V., and Berni, J. A. J.: Fluorescence, temperature and narrow-band indices acquired from a UAV platform for water stress detection using a microhyperspectral imager and a thermal camera, Remote Sens. Environ., 117, 322-337, https://doi.org/10.1016/j.rse.2011.10.007, 2012.

Zarco-Tejada, P. J., Guillén-Climent, M. L., Hernández-Clemente, R., Catalina, A., González, M. R., and Martín, P.: Estimating leaf carotenoid content in vineyards using high resolution hyperspectral imagery acquired from an unmanned aerial vehicle (UAV), Agr. Forest Meteorol., 171-172, 281-294, https://doi.org/10.1016/j.agrformet.2012.12.013, 2013.

Zhang, C. and Kovacs, J. M.: The application of small unmanned aerial systems for precision agriculture: a review, Precision Agric., 13, 693-712, https://doi.org/10.1007/s11119-012-9274$5,2012$.

Zhang, K., Kimball, J. S., and Running, S. W.: A review of remote sensing based actual evapotranspiration estimation, Wiley Interdisciplin. Rev. Water, 3, 834-853, https://doi.org/10.1002/wat2.1168, 2016.

Zhang, Y., Pan, M., and Wood, E. F.: On Creating Global Gridded Terrestrial Water Budget Estimates from Satellite Remote Sensing, Surv. Geophys., 37, 249-268, https://doi.org/10.1007/s10712-015-9354-y, 2016a.

Zhang, Y., Peña-Arancibia, J. L., McVicar, T. R., Chiew, F. H. S., Vaze, J., Liu, C., Lu, X., Zheng, H., Wang, Y., Liu, Y. Y., Miralles, D. G., and Pan, M.: Multi-decadal trends in global terrestrial evapotranspiration and its components, Scient. Rep., 6, 19124, https://doi.org/10.1038/srep19124, 2016b.

Zreda, M., Shuttleworth, W. J., Zeng, X., Zweck, C., Desilets, D., Franz, T., and Rosolem, R.: COSMOS: the COsmic-ray Soil Moisture Observing System, Hydrol. Earth Syst. Sci., 16, 40794099, https://doi.org/10.5194/hess-16-4079-2012, 2012.

Zuckerberg: Technology behind Aquila, https://www.facebook. com/notes/mark-zuckerberg/the-technology-behind-aquila/ 10153916136506634/, last access: 10 November 2016. 